Published in final edited form as:

Nature. 2014 November 27; 515(7528): 523-527. doi:10.1038/nature13953.

\title{
A positional Toll receptor code directs convergent extension in Drosophila
}

\author{
Adam C. Paré ${ }^{1}$, Athea Vichas ${ }^{1}$, Christopher T. Fincher ${ }^{1}$, Zachary Mirman ${ }^{1}$, Dene L. Farrell ${ }^{1}$, \\ Avantika Mainieri $^{1}$, and Jennifer A. Zallen ${ }^{1, a}$ \\ ${ }^{1}$ Howard Hughes Medical Institute and Developmental Biology Program, Sloan Kettering \\ Institute, New York, NY 10065, USA
}

\section{Summary}

Elongation of the head-to-tail body axis by convergent extension is a conserved developmental process throughout metazoans. In Drosophila, patterns of transcription factor expression provide spatial cues that induce systematically oriented cell movements and promote tissue elongation. However, the mechanisms by which patterned transcriptional inputs control cell polarity and behavior have long been elusive. We demonstrate that three Toll family receptors, Toll-2, Toll-6, and Toll-8, are expressed in overlapping transverse stripes along the anterior-posterior axis and act in combination to direct planar polarity and polarized cell rearrangements during convergent extension. Simultaneous disruption of all three receptors strongly reduces actomyosin-driven junctional remodeling and axis elongation, and an ectopic stripe of Toll receptor expression is sufficient to induce planar polarized actomyosin contractility. These results demonstrate that tissue-level patterns of Toll receptor expression provide spatial signals that link positional information from the anterior-posterior patterning system to the essential cell behaviors that drive convergent extension.

\begin{abstract}
A central question in developmental biology is how the diverse structures of multicellular tissues are generated on a cellular and molecular level. Convergent extension, in which a tissue narrows along one axis and lengthens in a perpendicular direction, is a conserved tissue remodeling process that elongates the head-to-tail body axis of many animals. Cell intercalation provides the driving force for convergent extension in frogs, fish, flies, chicks, and mice ${ }^{1-5}$. This process is characterized by a striking directionality in which hundreds of cells align their movements along a common axis. In epithelial tissues, cell intercalation is mediated by spatially regulated actomyosin contractility, which induces locally oriented cell rearrangements that produce concerted elongation at the tissue scale ${ }^{6-10}$. This mechanism was first discovered in Drosophila ${ }^{6-10}$ and has since been shown to promote convergent extension in the vertebrate neural plate, primitive streak, kidney, and notochord ${ }^{11-16}$. In
\end{abstract}

\footnotetext{
${ }^{\text {a }}$ Correspondence: Jennifer A. Zallen (zallenj@ mskcc.org), Howard Hughes Medical Institute, Developmental Biology Program, Sloan Kettering Institute, New York, NY 10065.

Author contributions

A.C.P., A.V. and J.A.Z. designed the study. A.C.P., A.V., C.F. and Z.M. performed the experiments, D.L.F. and A.M. performed the computational analysis, and A.C.P. and J.A.Z. wrote the manuscript. All authors participated in analysis of the data and in producing the final version of the manuscript.

The authors declare no competing financial interests.
} 
Drosophila and Xenopus, the spatial cues that align cell movements with the tissue axes are not cell-intrinsic or long-range secreted signals. Instead, contact-dependent signals provide the critical spatial inputs that orient cell intercalation ${ }^{6,17,18}$. In the Drosophila embryo, these inputs are mediated by the pair-rule transcription factors Eve and Runt, components of the embryonic AP patterning system that are expressed in transverse stripes along the anteriorposterior (AP) axis ${ }^{19}$. When these striped patterns are disrupted, either in eve or runt mutants or in embryos overexpressing Eve or Runt at high levels, intercalary behaviors are reduced and misoriented ${ }^{8,17,20}$ and the actomyosin contractile machinery becomes mislocalized within cells ${ }^{6,8,21}$. Ectopic Eve or Runt expression perpendicular to their normal stripes is sufficient to reorient planar polarity in intercalating cells ${ }^{6}$, demonstrating that spatial patterns of Eve and Runt activity provide instructive polarity cues. However, the connection between transcriptional information provided by striped patterns of Eve and Runt activity and the effector molecules that generate polarized cell behavior during convergent extension has long been elusive $e^{2,22}$.

To identify the targets of Eve and Runt that direct cell behavior during convergent extension, we performed RNA sequencing on Drosophila embryos co-injected with eve and runt double-stranded RNAs (dsRNAs). Compared with water-injected controls, 42 genes were differentially expressed ( $p<0.01$, Extended Data Fig. 1a-c, Supplementary Table 1). As Eve and Runt can function as transcriptional repressors, we focused on the 24 genes that were significantly upregulated by eve/runt RNA interference (RNAi). This group included Toll- 8 (Tollo), which encodes a single-pass transmembrane protein containing 27 extracellular leucine-rich repeats (LRRs) and a conserved cytoplasmic Toll/interleukin-1 receptor (TIR) domain. The related gene Toll-2 (18-wheeler) was also upregulated by eve/runt RNAi. Toll-2 and Toll-8 belong to the Toll receptor family that regulates innate immunity in arthropods and vertebrates ${ }^{23-27}$. The founding member of this family, Toll, is essential for dorsal-ventral patterning in Drosophila ${ }^{28}$, and the paralogs Toll-2, Toll-6, Toll-7, and Toll- 8 are expressed in stripes in patterns reminiscent of the pair-rule genes ${ }^{29-31}$. As members of this family can influence cell adhesion and epithelial morphology ${ }^{31-35}$, we focused on Toll receptors as candidate effectors of Eve and Runt that could regulate polarized cell behavior during convergent extension.

To determine whether the striped expression of Toll family receptors requires Eve and Runt activity, we analyzed their expression by fluorescence in situ hybridization ${ }^{36}$. In wild-type embryos, Toll-2 is expressed in 13 stripes in the germband, of which the odd-numbered stripes coincide with Runt (Fig. 1a,d; Extended Data Fig. 2a,d) ${ }^{29-31}$. Toll-6 and Toll-8 are each expressed in 6 partially overlapping stripes, with Toll- 6 expressed anterior to the stripes of high Toll-2 expression and Toll-8 expressed between them (Fig. 1b,c,e,f,m,n; Extended Data Fig. 2b,c,e,f). Toll-7 was detected at low levels during axis elongation (Supplementary Table 1, Extended Data Fig. 1d). The 13 Toll-2 stripes collapsed into 6 broad stripes in eve and runt mutants (Fig. 1g,j). Toll- 6 levels were reduced and Toll- 8 was nearly absent in eve mutants (Fig. 1h,i), whereas Toll- 6 and Toll- 8 were upregulated and more uniformly expressed in runt mutants (Fig. 1k,1). The Toll-8 protein fused to YFP and expressed from its endogenous regulatory sequences localized to the plasma membrane, with cells in the middle of each stripe showing stronger signal with no obvious overall planar polarity (Fig. 
10). Therefore, neighboring cells along the AP axis express different combinations of Toll-2, Toll-6, and Toll-8 in an Eve- and Runt-dependent pattern (Fig. 1p).

We next investigated whether Toll-2, Toll-6, and Toll-8 are required for convergent extension, as predicted for the targets of Eve and Runt that control cell behavior. The wildtype germband epithelium doubles in length along the AP axis within the first $30 \mathrm{~min}$ of elongation (2.00 \pm 0.07 -fold increase in length) (Fig. 2a-c). Axis elongation occurred normally in Toll-8 single mutants (Fig. 2c; Extended Data Fig. 3a,b,f). Therefore, we postulated that multiple Toll receptors act together to regulate cell behavior during elongation. To disrupt multiple Toll receptors simultaneously, we injected dsRNAs that specifically target Toll-2 and Toll-6 into Toll-8 null mutant embryos (Extended Data Fig. 1e,f). Embryos defective for any one receptor elongated to a wild-type extent (Fig. 2b,c; Extended Data Fig. 3a,b,f). By contrast, axis elongation was reduced by nearly $20 \%$ in embryos defective for Toll-2 and Toll-6(1.83 \pm 0.03 -fold, $p<0.02)$ and nearly $40 \%$ in embryos defective for Toll-2, Toll-6, and Toll-8 (1.61 \pm 0.04 -fold, $p<0.001)$ (Supplementary Video 1), similar to eve and runt mutants (1.68 \pm 0.05 -fold in eve and 1.64 \pm 0.02 -fold in runt, $p<0.01$ ) (Fig. 2c; Extended Data Fig. 3d,f). In addition, we used TAL effector nucleases (TALENs) $^{37}$ to generate embryos that completely lack Toll-2, Toll-6, and Toll-8, and found that Toll-2,6,8 triple mutants display a significant reduction in axis elongation (Fig. 2b,c; Extended Data Fig. 3e,f; Extended Data Fig. 4; Supplementary Video 2). These results demonstrate that Toll-2, Toll-6, and Toll-8 act in combination to regulate axis elongation.

Cell intercalation is the primary mechanism driving axis elongation in Drosophila ${ }^{7,8,17}$. To determine whether Toll receptors are required for cell intercalation, we used automated methods to track cell behavior in time-lapse movies ${ }^{21,38}$. In embryos defective for any one Toll family receptor, the frequency of cell intercalation was similar to wild type (Fig. 2f; Extended Data Fig. 3a,b,g-i). By contrast, cell intercalation was reduced by $17 \%$ in embryos defective for Toll-2 and Toll- 6 ( $p<0.03$ ), 19\% in embryos defective for Toll- 6 and Toll- 8 $(p<0.02)$, and more than $30 \%$ in Toll-2,6,8 triple mutants ( $p<0.001)$, accompanied by slower edge contraction (Fig. 2e,f; Extended Data Fig. 3c-e,g-j). Toll-2,6,8 triple mutants were similar to runt mutants, although not quite as severe as eve mutants (Fig. 2e,f; Extended Data Fig. 3e,g-i). These results demonstrate that Toll-2, Toll-6, and Toll-8 promote cell intercalation during axis elongation.

For cell rearrangements to produce tissue elongation, intercalation must occur directionally through the contraction of interfaces between anterior and posterior neighbors (AP edges) and the formation of interfaces between dorsal and ventral neighbors (DV edges) (Fig. $2 \mathrm{~d})^{7,8}$. Contracting edges were correctly oriented in Toll receptor-defective embryos (Extended Data Fig. 3k). By contrast, in more than one-third of cell rearrangements in Toll-2,6,8 mutants, new edges failed to form, were unstable, or formed in the wrong direction (36 $\pm 4 \%$ of edges in Toll-2,6,8 vs. 9.5 $\pm 0.3 \%$ in wild type, $p<0.0001$ ), similar to the defects in eve and runt mutants (34 $\pm 4 \%$ in eve and $37 \pm 1 \%$ in runt, $p \unlhd) .01$ ) (Fig. $2 \mathrm{~g}$ ). Embryos defective for Toll-2 alone had intermediate defects, indicating that the other Toll receptors cannot fully substitute for Toll-2 in orienting edge formation. These results indicate that Toll receptors are required for rapid edge contraction and directional edge formation, suggesting that a common mechanism underlies both steps of cell rearrangement. 
Physical forces generated by the intercalation of subsets of cells can reinforce myosin polarity ${ }^{10}$ and trigger passive cell stretching in neighboring cells ${ }^{20}$, perhaps allowing for substantial elongation in embryos that express a partial complement of Toll receptors.

Cell intercalation in Drosophila is driven by the planar polarized activity of myosin II, which promotes the contraction of AP edges ${ }^{6-10}$, and Par-3, which excludes myosin and stabilizes adhesion at DV edges ${ }^{6,21}$. To determine whether Toll receptors are required for myosin II and Par-3 localization, we used automated methods to analyze planar polarity at single-cell resolution $^{39}$. In wild-type embryos, myosin II was enriched 1.30 \pm 0.02 -fold at AP edges and Par-3 was enriched 1.71 \pm 0.03 -fold at DV edges (Fig. 3a,e,f). By contrast, Toll-2,6,8 mutants had a $47 \%$ reduction in myosin II planar polarity $(1.16 \pm 0.01, p<0.0001)$ and a $48 \%$ reduction in Par-3 planar polarity $(1.37 \pm 0.02, p<0.0001)$ (Fig. 3b,e,f). Similar defects were observed in runt mutants, although planar polarity was more severely affected in eve mutants (1.21 \pm 0.01 for Par-3 and 1.09 \pm 0.02 for myosin, $p<0.0001$ ) (Fig. 3c-f; Extended Data Fig. 5). Toll receptor expression is reduced in eve mutants, whereas runt mutants have increased expression (Fig. 1g-1), suggesting that distinct mechanisms may underlie the defects in these two backgrounds. Apical-basal polarity was unaffected in Toll receptor mutants (Extended Data Fig. 31), and planar polarity was not further reduced in Toll-2,6,7,8 quadruple mutants (Extended Data Fig. 5g,h). These results demonstrate that Toll-2, Toll-6 and Toll-8 act together to regulate myosin II and Par-3 planar polarity.

Par-3 and myosin II planar polarity displayed regional differences in Toll-2 mutants. Planar polarity occurred normally in Toll-8-expressing cells, most of which also express Toll-6, but was significantly reduced in Toll-8-negative cells, the majority of which do not express any Toll receptors (Fig. 3e,g,i; Extended Data Fig. 6a). Similarly, in Toll-6,8 mutants, Toll-2expressing cells had wild-type planar polarity, whereas cells that did not express any of these receptors had significant defects (Fig. 3h,j). Therefore, embryos expressing only one or two Toll receptors have localized planar polarity defects in the regions of missing receptor expression.

In eve mutants, which almost completely lack planar polarized myosin, residual myosin cables still form at the posterior boundaries of Toll-2 stripes (Fig. 4d; Extended Data Fig. $6 \mathrm{~b}, \mathrm{c})$, suggesting that differences in Toll receptor activity may induce planar polarity. To test this, we expressed Toll-2 and Toll-8 in stripes in the late embryo using the engrailed-Gal4 driver. The anterior boundary of each engrailed stripe is situated anterior to the denticleforming cells, in a region where myosin II is not strongly planar polarized (Fig. 4a). Ectopic Toll-2 or Toll-8 led to a strong recruitment of myosin II to the anterior boundary of the engrailed domain (Fig. 4b,c,e; Supplementary Videos 3-5) and increased contractile activity at this boundary, as measured by laser ablation (Fig. 4f). These results demonstrate that local differences in Toll- 2 or Toll- 8 expression are sufficient to induce myosin planar polarity in vivo.

Drosophila Toll receptors are known to bind to Spätzle/DNT neurotrophin-related growth factors ${ }^{23,28,40,41}$, but the ligands detected by Toll receptors during convergent extension are not known. In one model, heterophilic interactions between receptors expressed on adjacent stripes of cells could induce actomyosin contractility at AP cell edges. Alternatively, 
homophilic interactions between receptors expressed in the same stripe could suppress actomyosin contractility and stabilize adhesion at DV edges. To investigate these possibilities, we tested for interactions between Toll receptors in Drosophila S2R+ cells ${ }^{42}$. Cells expressing Toll-2 displayed increased affinity for a soluble, pentamerized form of the Toll-8 extracellular domain (Fig. 5a,b). By contrast, cells expressing Toll-2 displayed decreased affinity for the Toll-2 extracellular domain (Fig. 5c,d). These results indicate that Toll-2 and Toll-8 can interact in a heterophilic manner in cultured cells.

To test whether Toll receptors can promote interactions between cells, we performed cellmixing experiments. Drosophila S2R+ cells normally do not aggregate, but cells expressing Toll-2, Toll-6, or Toll-8 aggregated with untransfected cells at high frequency, indicating that these receptors can bind to proteins present on S2R+ cells (Fig. 5e,f,k) (1,32 $^{31}$. Homophilic interactions between cells were not enhanced by Toll receptor expression (Fig. 5k). By contrast, Toll-2-positive cells formed extensive heterophilic contacts with cells expressing Toll-6 and/or Toll-8, creating chains of cells expressing alternating Toll receptors (Fig. 5gk). Heterophilic interactions were not observed between cells expressing Toll-6 and Toll-8, which are often coexpressed within the same stripes (Fig. 1p). These results indicate that Toll-2 can promote heterophilic interactions with cells expressing Toll-6 or Toll-8. Embryos expressing any one receptor still display significant planar polarity and intercalary behavior, suggesting that these proteins also interact with additional binding partners to generate planar polarity.

Together, these results demonstrate that the spatial signals that establish planar polarity and direct polarized cell behavior during convergent extension in Drosophila are encoded at the cell surface by three Toll family receptors expressed in overlapping stripes along the AP axis of the embryo. Simultaneous disruption of Toll-2, Toll-6, and Toll-8 significantly impairs planar polarity, cell intercalation, and convergent extension, and removing one or two receptors disrupts planar polarity in distinct subsets of cells, indicating that these proteins serve nonredundant and highly localized functions. These findings support a model in which planar polarity is induced by interactions between neighboring cells with different levels of Toll receptor activity (Fig. 51). Therefore, Drosophila Toll receptors provide the basis of a spatial code that translates patterned Eve and Runt transcriptional activity into planar polarized actomyosin contractility, linking positional information provided by the embryonic AP patterning system to the essential cell behaviors that drive convergent extension. The Toll receptor code is incomplete in certain regions, such as the parasegmental boundaries, suggesting the existence of additional polarity cues at these interfaces. Toll-2,6,8 mutants are similar to runt mutants with respect to all measures of cell rearrangement and planar polarity, but are not as severe as eve mutants. Thus, although Toll-2,6,8 mutants recapitulate much of the eve mutant phenotype, Eve likely has additional targets important for planar polarity.

Toll family receptors have a highly conserved structure in vertebrates and invertebrates, including extracellular LRR motifs that are often present in proteins involved in cell adhesion and cell-cell recognition ${ }^{43}$. Although individual receptors are not orthologous between flies and humans ${ }^{25}$, mammalian Toll-like receptors are required for epithelial regeneration and wound healing, processes that involve dynamic and spatially regulated 
changes in cell adhesion ${ }^{44-46}$. In the innate immune system, pathogen detection by Toll family receptors activates transcriptional pathways mediated by NF- $\kappa$ B and MAP kinase signaling ${ }^{23-26}$. However, the spatial information provided by patterned Toll receptor expression in Drosophila, as well as the rapid timescale of cell rearrangements during convergent extension, suggest a more direct connection between Toll receptor signaling and the cellular contractile machinery. Consistent with this possibility, activation of mammalian Toll-like receptors in dendritic cells induces a rapid remodeling of the actin cytoskeleton ${ }^{47}$ and mammalian Toll-like receptors can inhibit neurite outgrowth and trigger rapid growth cone collapse in neurons ${ }^{48,49}$, reminiscent of Toll receptor functions in the Drosophila nervous system ${ }^{40,41,50}$. Elucidating the mechanisms that link Toll family receptors to dynamic changes in cell polarity and behavior may provide insight into conserved and relatively unexplored aspects of Toll receptor signaling.

\section{Methods}

\section{Drosophila stocks and genetics}

The following alleles were used: Toll-2 $2^{\Delta 76}$ (a deletion of $450 \mathrm{bp}$ of the open reading frame and $2.3 \mathrm{~kb}$ of upstream sequence) $)^{34}$, Toll- $8^{59}$ (a deletion of the entire open reading frame $)^{52}$, Toll- $8^{145}$ (a $1.2 \mathrm{~kb}$ deletion in the 5' UTR) ${ }^{35}$, eve ${ }^{\mathrm{R} 13}$ (a frameshift that removes part of the homeodomain and the transcriptional repression domain) ${ }^{53}$, runt ${ }^{\mathrm{LB} 5}$ (a deletion of the entire open reading frame $)^{54}$, Toll- $\sigma^{1 \mathrm{~B}}$, Toll- $\sigma^{\mathrm{A}}$, and Toll- $7^{14 \mathrm{~F}}$ (early frameshift mutations, this study). Toll- 8 mutant embryos were the progeny of Resille-GFP; Toll- $8^{59 / 145}$ flies. Toll-2,6,8 triple mutants in Fig. 2 and Extended Data Fig. 3 were the progeny of Toll-2 ${ }^{\Delta 76} / \mathrm{CyO}$, $t w i-$ Gal4, UAS-GFP; Toll- ${ }^{59}$, Toll- $\sigma^{5 \mathrm{~A}}$, Spider-GFP/eve-YFP flies and were identified for live imaging by the absence of fluorescence from an eve-YFP transgene ${ }^{55}$ (visible before imaging) and the absence of fluorescence from the $C y O$, $t w i-G a l 4, U A S$-GFP balancer (visible after imaging). Toll-2,6,8 triple mutants in Fig. 3 and Extended Data Fig. 5 were the progeny of Toll-2 $2^{\Delta 76 /+}$; Toll- $8^{59}$, Toll- $6^{\mathrm{B}} /$ myosin-GFP flies and were identified by the absence of Toll- 2 and Toll- 8 transcripts by in situ hybridization. The double-mutant chromosomes Toll-7, Toll-2 and Toll-8, Toll- 6 were created using TALENs ${ }^{37}$ to induce Toll-7 and Toll-6 null mutations on the Toll-2 $2^{\Delta 76}$ and Toll- $8^{59}$ chromosomes, respectively (Extended Data Fig. 4). Cell outlines were labeled with Spider-GFP (Fig. 2, Extended Data Fig. 3, and Supplementary Video 2), Resille-GFP (gift of A. Debec) (Fig. 2, Extended Data Fig. 3, and Supplementary Video 1), and UAS-gap43-mCherry ${ }^{56}$ (Fig. 4f). Myosin II was visualized with a GFP fusion to the regulatory light chain expressed from the endogenous promoter ${ }^{57}$. In Fig. 4a-c,e, embryos were the progeny of engrailed-Gal4 crossed to the following genotypes: (1) UASp- $\beta$-catenin [ $\triangle C]-H A$ (II); myosin-GFP(III), (2) myosin-GFP (II); UASp-Toll-2-HA (III), (3) UASp-Toll-8-HA (II); myosin-GFP(III). In Fig. 4f, embryos were the progeny of engrailed-Gal4 females crossed to UAS-gap43-mCherry males or UASToll-8-Venus; UAS-gap43-mCherry males.

Toll-8-YFP was expressed from its endogenous regulatory sequences using BAC recombineering to introduce SYFP2, a fast-folding variant of YFP (gift of B. Glick), into BAC CH321-67E02, which spans $34 \mathrm{~kb}$ upstream and $27 \mathrm{~kb}$ downstream of the Toll- 8 open reading frame. To create UASp-Toll-2-HA and UASp-Toll-8-HA, the full-length Toll-2 and 
Toll-8 open reading frames were PCR amplified with primers containing a C-terminal HA tag and cloned into the pENTR/DTOPO vector (Invitrogen). For UASp-Toll-8-Venus, fulllength Toll- 8 was cloned into pENTR/D-TOPO, and Venus was subsequently cloned into the Asc I site. UAS constructs were recombined into pUASp-w-attB (gift of Mike Buszczak) using Gateway cloning (Invitrogen). UASp-Toll-8-HA, UASp-Toll-8-Venus and the Toll-8YFP BAC were targeted to the attP40 site on chromosome II and UASp-Toll-2-HA was targeted to the attP2 site on chromosome III by $\Phi \mathrm{C} 31$-mediated transgenesis (Genetic Services).

\section{dsRNA generation}

Double-stranded RNAs (dsRNAs) designed to target eve, runt, Toll-2, Toll-6, Toll-8, and Toll-3 (negative control) were transcribed from PCR-generated templates containing T7 promoters on both ends. PCR templates (500 ng) were transcribed using the T7 MEGAscript kit (Life Technologies). The effects of Toll-2/ Toll-6 dsRNA injections into Toll-8 ${ }^{59 / 145}$ were confirmed with a second independent set of dsRNAs (\#2 below) (Extended Data Fig. 3d). The dsRNAs were purified using gel-filtration spin columns (mini Quick Spin RNA Columns; Roche), precipitated with two volumes of isopropanol, washed with $75 \%$ ethanol, and resuspended in nuclease-free $\mathrm{H}_{2} \mathrm{O}$. The dsRNA templates were amplified using the following primer pairs (all preceded by a T7 promoter sequence 5' -

TAATACGACTCACTATAGGGAGA-3'): eve (5'-TGCCTATCCAGTCCGGATAACTCC-3' and 5'-CACACCCAGTCCGGTATAGCAGG-3'); runt (5'-

ATGGTGGCCAACAACACACAGGTC-3' and 5'-

GCTTTGCTGTAGCTGGCGATCTGC-3'); Toll-2\#1 (5'-

AGTTTGAATCGAAACGCGAG-3' and 5'-GGACACTGCACCGGATGT-3'); Toll-2\#2

(5'-GCCTGCAACACAACAACATC-3' and 5' - TCAATGTGGCCAATGGAGT-3'); Toll-6 \#1 (5'-ATCGGCCAAAAAGAGCAGTA-3' and 5'-AGCAGCGTGTGCAGATTATT-3'); Toll-6\#2 (5'-AATCAACTTCAGCGCATTGG-3' and 5'AATCAACTTCAGCGCATTGG-3'); and Toll-3 (5'-GAGCCTTGAACATTTGGAGC-3' and 5'-CAGTTTCGCTGGAAGGTGAT-3').

\section{Embryo injections}

For RNA sequencing, precellularized wild-type (Oregon-R) embryos (30-60 min after egglaying) were dechorionated for $3 \mathrm{~min}$ in 50\% bleach, immobilized with glue on coverslips, desiccated for $\sim 7 \mathrm{~min}$ in an air-tight container with Drierite, covered with a 1:1 mixture of halocarbon oil 700 and 27 (Sigma), and micro-injected ventrally with eve and runt dsRNAs $\left(1 \mu \mathrm{g} / \mu \mathrm{l}\right.$ each). Injected embryos were allowed to develop at $18^{\circ} \mathrm{C}$ in a humid chamber until just prior to mesodermal invagination (late stage 5/early stage 6 ). Then, using a fine paintbrush, properly staged embryos were gently separated from the coverslip and transferred in a small drop of oil into $50 \mu \mathrm{l}$ Trizol Reagent (Life Technologies). Approximately 60 staged embryos were collected per sample (3 biological replicates/ condition) and frozen at $-80^{\circ} \mathrm{C}$. Control embryos were injected with water but were otherwise treated identically.

For time-lapse imaging, pre-cellularized Resille-GFP embryos or the progeny of ResilleGFP; Toll- $8^{59} /$ Toll- $8^{145}$ flies were injected dorsally (30-60 min after egg laying) with 
dsRNA, as described above. Embryos injected with a single dsRNA were injected with $3 \mu \mathrm{g} /$ $\mu \mathrm{l}$ dsRNA, and embryos injected with two dsRNAs were injected with $1.5 \mu \mathrm{g} / \mu \mathrm{l}$ each dsRNA. The dsRNA-injected embryos were aged at $18^{\circ} \mathrm{C}$ in a humid chamber until just prior to mesodermal invagination, detached from the coverslip using a fine paintbrush, and mounted for imaging in a thin layer of halocarbon oil between a coverslip and an oxygenpermeable membrane (YSI Life Sciences). Uninjected embryos were dechorionated immediately prior to imaging and mounted similarly.

\section{RNA sequencing}

We compared the transcriptomes of eve and runt dsRNA-injected ( $1 \mu \mathrm{g} / \mu \mathrm{l}$ each) embryos with water-injected controls using RNA sequencing (50-bp paired end reads; 20 million reads/sample). Total RNA was extracted from $\sim 60$ staged embryos/sample, in triplicate, using a modified version of the Trizol extraction protocol. Briefly, excess halocarbon oil was removed using a pipet, and the embryos were ground in microfuge tubes using RNase-free plastic pestles. An additional $450 \mu \mathrm{l}$ Trizol reagent was added, and the samples were incubated for $5 \mathrm{~min}$ at room temperature. Next, $100 \mu \mathrm{l}$ chloroform was added, and the samples were incubated for $3 \mathrm{~min}$ at room temperature. Finally, the organic and aqueous phases were separated by centrifugation at $12,000 \mathrm{~g}$ for $15 \mathrm{~min}$. From this point onward, the manufacturer's protocol was followed. RNA sequencing was carried out by the MSKCC Genomics Core using the HiSeq platform (Illumina) with 50-bp paired-end reads and 20 million reads per sample. Fold-change analysis was carried out by the MSKCC Bioinformatics Core based on the number of reads per gene. Toll- 8 (Tollo) and Toll-2 (18W) were strongly expressed and Toll- 6 and Toll-7 were weakly expressed in the late stage 5/ early stage 6 wild-type embryos used for analysis. Toll (TI) is maternally and zygotically expressed at this stage ${ }^{51}$. Expression of the other Drosophila Toll family genes was not detected. The complete dataset is available on the Gene Expression Omnibus (GSE61689).

\section{Quantitative RT-PCR}

Total RNA was isolated from dsRNA-injected embryos and uninjected controls, as described above. For each sample, $1 \mu \mathrm{g}$ total RNA was DNase-treated and then reverse-transcribed using the High Capacity cDNA Reverse Transcription Kit (Applied Biosystems). Then $50 \mathrm{ng}$ cDNA was amplified in each qRT-PCR reaction using predesigned TaqMan gene expression assays for Toll-2(Dm01841837_s1), Toll-6(Dm01822826_s1), Toll-7(Dm01821614_s1), Toll-8(Dm01837153_s1), and RpL32 (Dm02151827_s1) (Applied Biosystems). Reactions were carried out using a 7900HT Fast Real-Time PCR system (Applied Biosystems). Relative expression levels were quantified using the $2^{-\Delta \Delta C(T)}$ method ${ }^{58}$. The results are representative of three biological replicates and expression was normalized to $R p L 32$ within each sample.

\section{TALEN-mediated mutagenesis}

The TAL Effector Nucleotide Targeter 2.0 program (Cornell University) was used to design left and right TALEN targeting sequences immediately downstream of the transcriptional start sites of Toll- 6 and Toll-7. Targeting sequences contained upstream T nucleotides, were $15-20 \mathrm{bp}$ in length, and the pairs were separated by 15-16-bp spacer regions. The targeting sequences were 5'-TGATCTACTATATGCTACTCA-3' (left) and 5'- 
GGCCCAGGATCAGCAGCACA-3' (right) for Toll-6, and 5'-TGGCGGCAATCCTGCT-3' (left) and 5'-CTCCTGGAGTCTCGCGGTCGA-3' (right) for Toll-7. The spacer regions for Toll-6 (5'-TACTGCCCGTGGTCCT-3') and Toll-7 (GCTCCTGCTCGGGTT-3') contained Ava II and Ava I restriction sites, respectively, which were used to screen for deletions. The Golden Gate TALEN $2.0 \mathrm{kit}^{37}$ was used to construct the custom TALEN arrays (the NN RVD was used for $\mathrm{G}$ nucleotides). The final constructs were cloned into the RCIscriptGoldyTALEN destination vector, and the mMessage mMachine T3 Kit (Invitrogen) was used to transcribe the TALEN RNAs. The Poly(A) Tailing Kit (Ambion) was used to add poly(A) tails to the RNA products, which were then purified using mini Quick Spin RNA columns (Roche).

Mixtures of left and right Toll-7 or Toll-6 TALEN mRNAs ( $250 \mathrm{ng} / \mu \mathrm{l}$ each in $\mathrm{H}_{2} 0$ ) were injected posteriorly into Toll-2 $2^{\Delta 76}$ and Toll- $8^{59}$ embryos, respectively. Injected males were individually crossed to balancer females, and the resulting F1 male progeny were again individually backcrossed to balancer females to establish stocks. DNA was extracted from the F1 males post-mating by crushing the flies in lysis buffer $(10 \mathrm{mM}$ Tris $\mathrm{pH} 8.2,1 \mathrm{mM}$ EDTA, $25 \mathrm{mM} \mathrm{NaCl}$, and $200 \mu \mathrm{g} / \mathrm{ml}$ proteinase $\mathrm{K}$ ) and then incubating them for $30 \mathrm{~min}$ at $37^{\circ} \mathrm{C}$ and $2 \mathrm{~min}$ at $95^{\circ} \mathrm{C}$. The following primers were used to amplify the genomic sequence surrounding the spacer regions: Toll-6 (5'-CTTTGGCCAGCCAGTGGAATTG-3' and 5'AACCAGATGGGCGAAAGATTGC-3') and Toll-7 (5'ATGTGCGCTTAGTGAAACAGTG-3' and 5'-GTCTGCAACCTGGCAAATACTG-3'). The PCR products were digested overnight at $37^{\circ} \mathrm{C}$ with Ava II or Ava I. Products showing restriction site loss were sequenced, and lines containing frame-shift mutations leading to premature translation termination were kept.

\section{Fluorescence in situ hybridization and immunohistochemistry}

Simultaneous fluorescence in situ hybridization and immunohistochemistry were carried out using the acetone permeabilization method ${ }^{36,59}$. Hapten-tagged antisense RNA probes ( 1,000 nt) were transcribed from PCR-generated templates containing a 3' T7 promoter, and probes were labeled by incorporating digoxigenin- or dinitrophenyl-tagged UTP nucleotides during transcription ${ }^{60}$. Primer sequences were: Toll-2 (5'-

TGCAACTGCTCAATCTCACC-3' and 5'taatacgactcactatagggagaTACTCCGACTCGATGCTGTG-3'); Toll-6 (5'ACCTTTGTGGGTCTGATTCG-3' and 5'taatacgactcactatagggagaTGCAGGATTTCTTGCAGTTG-3'); Toll-8 (5'CTTCGGAGAGTTGGCTGAAC-3' and 5'taatacgactcactatagggagaTTCTCATTCGTTCGTTGCTG -3'). Probes were fragmented by incubation in carbonate buffer $\left(60 \mathrm{mM} \mathrm{Na}_{2} \mathrm{CO}_{3}\right.$ and $\left.40 \mathrm{mM} \mathrm{NaHCO}_{3}, \mathrm{pH} 10.2\right)$ at $65^{\circ} \mathrm{C}$ for $30 \mathrm{~min}$. Hybridized probes were detected with mouse anti-digoxigenin (1:250; Jackson ImmunoResearch) or rabbit anti-dinitrophenyl (1:250; Molecular Probes) antibodies.

Toll-8-YFP embryos were fixed for $15 \mathrm{~min}$ in a 1:1 mixture of $18 \%$ formaldehyde (in $0.5 \times$ PBS) and heptane and manually devitellinized. Embryos in engrailed-Gal4 misexpression experiments were fixed for $1 \mathrm{~h}$ in a 1:1 mixture of $3.7 \%$ formaldehyde (in $1 \times \mathrm{PBS}$ ) and heptane and manually devitellinized. Antibodies used were guinea pig anti-Runt $(1: 1000)^{61}$, 
rabbit anti-GFP (1:150; Torrey Pines), guinea pig anti-Par-3 $(1: 100)^{8}$, and rat anti-HA (1:500; Roche). Primary antibodies were detected with Alexa Fluor-labeled secondary antibodies (1:500; Molecular Probes). Embryos were mounted in ProLong gold (Molecular Probes) and imaged on a Zeiss LSM700 laser-scanning confocal microscope with a PlanNeofluor 40× 1.3 NA oil-immersion objective; z-slices (1.0- $\mu \mathrm{m}$ thick) were acquired in steps of $0.5 \mu \mathrm{m}$.

\section{Time-lapse imaging}

Live imaging was performed on embryos expressing Spider-GFP, Resille-GFP, or MyosinGFP. Embryos were imaged using Perkin Elmer UltraView VOX or RS5 spinning-disk confocal microscopes with Plan-Neo 40× 1.3 NA or Plan-Apo 40×/1.3 NA oil-immersion objectives (Zeiss). Images were acquired using the Volocity software program. For Fig. 2, Extended Data Fig. 3, and Supplementary Videos 1 and 2, image stacks were acquired every $15 \mathrm{~s}$ at $1-\mu \mathrm{m} z$-steps and three apical planes in the region of the adherens junctions were projected for analysis. For Supplementary Videos 3-5, image stacks were acquired every 30 $\mathrm{s}$ at $0.5-\mu \mathrm{m} \mathrm{z}$-steps and two apical planes were projected for analysis.

\section{Laser ablation}

Late stage 14/early stage 15 embryos were mounted in halocarbon oil and imaged using a Perkin Elmer RS5 spinning-disk confocal microscope with a Plan Neofluor 63× 1.4 NA oilimmersion objective (Zeiss), which was also used to focus the MicroPoint laser (Photonics Instruments). The velocity of edge retraction following ablation is predicted to be proportional to tension at the edge prior to ablation, assuming uniformity of tissue viscoelastic properties ${ }^{62}$. The laser was tuned to $365 \mathrm{~nm}$ and was used to ablate single cell interfaces at the anterior boundary of the engrailed expression domain, which was visualized by Gal4-dependent expression from UAS sequences present in the sqh-Gap43-mCherry transgene ${ }^{56}$. Image stacks were acquired every $3 \mathrm{~s}$ at $0.7-\mu \mathrm{m}$ z-steps and peak retraction velocities were measured in ImageJ.

\section{Cell culture}

The coding regions for the Toll-2 and Toll- 8 extracellular domains were cloned into the pENTR/D vector and then recombined into the pECIA14 expression vector (Addgene) using Gateway cloning. The pECIA14 vector contains an inducible $\mathrm{CuSO}_{4}$ promoter and a Cterminal human placental alkaline phosphatase gene ${ }^{42}$. The constructs were transfected into Drosophila S2R+ cells (split one day earlier) using Cellfectin II reagent (Life Technologies), and protein expression was induced with $1 \mathrm{mM} \mathrm{CuSO}_{4} 18 \mathrm{~h}$ post-transfection. The conditioned media was collected 3 days post-induction and concentrated for $15 \mathrm{~min}$ at 5,000 $\mathrm{g}$ using Ultra-4 Centrifugal Filter Units (100 kDa cutoff; Amnicon). Next, $1 \times$ Complete, EDTA-free Protease Inhibitor Cocktail (Roche) and $0.02 \%$ sodium azide were added, and the media was stored at $4^{\circ} \mathrm{C}$ until use.

$\mathrm{S} 2 \mathrm{R}+$ cells were maintained in Schneider's medium supplemented with $10 \%$ fetal calf serum at $25^{\circ} \mathrm{C}$. Cells were transfected with pActin5.1-GAL4 alone or in combination with UASToll-2-HA or UAS-Toll-8-HA. One day post-transfection, cells were adhered to polylysinecoated coverslips for $10 \mathrm{~min}$ and washed with $1 \times$ PBS. Cells were then incubated $10 \mathrm{~min}$ 
with the concentrated media from cells expressing pentameric alkaline phosphatase fusions to the Toll-2 or Toll-8 extracellular domains diluted in Schneider's complete medium (protein levels were previously estimated by Western blotting and normalized across samples). Cells were washed once with $1 \times$ PBS, fixed for 10 min with $4 \%$ formaldehyde/ PBS, washed 3 times with $1 \times$ PBS, and blocked for 15 min in blocking buffer (1\% BSA, $0.1 \%$ Triton, and $10 \mathrm{mM}$ glycine). Cells were stained with rat anti-HA (1:250; Roche) and rabbit anti-human placental alkaline phosphatase (1:250; Serotec) primary antibodies and Alexa 488- and Alexa 647-conjugated secondary antibodies (1:500; Molecular Probes), mounted in Prolong Gold (Molecular Probes), and imaged using a Zeiss LSM700 confocal with a Plan-Apo 40×/1.3 NA oil-immersion objective. Cortical AP intensity was quantified using ImageJ.

For cell mixing experiments, $\mathrm{S} 2 \mathrm{R}+$ cells were transfected with appropriate combinations of pActin5.1-GAL4, sqh-myosin-GFP, UAS-myosin-mCherry, UAS-Toll-2, UAS-Toll-6-HA, and UAS-Toll-8-HA plasmids. Growing cells were added to 6-well plates (2 ml Grace's medium/well) and transfected with $300 \mathrm{ng}$ each plasmid diluted in $200 \mu \mathrm{l}$ Grace's medium with $8 \mu \mathrm{l}$ Cellfectin II reagent (Invitrogen). The next day, transfected cells were counted using a hemocytometer, and $10^{6}$ cells from each condition $\left(2 \times 10^{6}\right.$ cells total $)$ were combined in a final volume of $2 \mathrm{ml}$ in $50 \mathrm{ml}$ Falcon tubes. The tubes were placed vertically on a tabletop shaker and gently agitated for $3 \mathrm{~h}$ at $100 \mathrm{rpm}$. A portion of each mixture $(600 \mu \mathrm{l})$ was pipetted using a blunt-cut P1000 tip and allowed to adhere to polylysine-coated coverslips for $45 \mathrm{~min}$. The semi-adherent cells were then washed once with $1 \times$ PBS, fixed for 10 min with $4 \%$ formaldehyde/PBS, washed 3 times with $1 \times$ PBS, and then mounted in Prolong Gold. Similar results were observed with the fluorescent markers reversed. We did not observe binding between cells expressing Toll- 6 or Toll- 8 and the extracellular domains of Toll-2 or Toll-8 in this assay (data not shown).

\section{Image analysis}

Time-lapse movies were segmented and analyzed using custom software implemented in MATLAB. The onset of elongation was $t=0$, set as the point at which the derivative of tissue AP length plotted over time intersects zero. Tissue length was measured as the long axis of an ellipse fit to the group of tracked cells. Cell rearrangements (neighbors lost/cell) were calculated as the number of cell boundaries that contracted to a vertex and did not reform over the course of the movie divided by the total number of tracked cells. Cells tracked $\geq 12.5$ min after $\mathrm{t}=0$ were analyzed for cell rearrangement and cells tracked from $\mathrm{t}=0$ until the end of the movie were analyzed for axis elongation. Edge contraction rate was analyzed at mid-stage 7 (in the period spanning 5-8 min after the onset of elongation, inclusive) and was the average rate of change in length over a sliding 15 -frame time window (15 s between frames) for all edges that ultimately contracted to a vertex and were oriented $75-90^{\circ}$ relative to the AP axis. The first-order derivatives of the time series for individual edges were identified using a Savitzky-Golay filter implemented in MATLAB. Edge formation errors were analyzed by visual inspection. Statistical analysis was performed using the f-test followed by the appropriate $t$-test for equal variance (Student's $t$-test) or unequal variance (Welch's t-test), using the value at $\mathrm{t}=30 \mathrm{~min}$ as the test statistic. $\mathrm{P}$ values were determined by comparison to the most appropriate control: wild-type Spider-GFP for comparison to mutant 
embryos expressing Spider-GFP, wild-type Resille-GFP for comparison to mutant embryos expressing Resille-GFP, and control-injected Resille-GFP (injected with Toll-3 dsRNA) for comparison to dsRNA-injected embryos expressing Resille-GFP.

Planar polarity was analyzed at single-cell resolution in fixed embryos using maximum intensity projections of the apical junctional domain. Cell boundaries were identified using custom segmentation software implemented in MATLAB. Myosin II and Par-3 intensity was the average pixel intensity along each edge, with the intensity of each pixel calculated as the maximum pixel intensity on a 5-pixel-wide line oriented perpendicular to the edge.

Following background subtraction based on the cytoplasmic intensities of the 20 closest cells, the ratio of the average intensity of AP edges (edges oriented $60-90^{\circ}$ to the AP axis) to the average intensity of DV edge $\left(0-30^{\circ}\right)$ was calculated for each cell, and a single average value was obtained for each embryo (full distributions shown in Extended Data Fig. 5). Cells without at least one AP and one DV edge were not scored (gray cells in Extended Data Fig. 6a). For Fig. 4d, the average fluorescence intensity at the indicated classes of AP edges was normalized to the average intensity of all edges within the same embryo. For Fig. 4e, the average myosin-GFP intensity at the anterior boundary of the engrailed domain was normalized to the average myosin-GFP intensity in the adjacent smooth cells. Increased myosin recruitment was not observed at the posterior boundary of the engrailed domain, although the formation of actin-based denticle structures in these cells may preclude induction of ectopic actomyosin polarity.

\section{Extended Data}

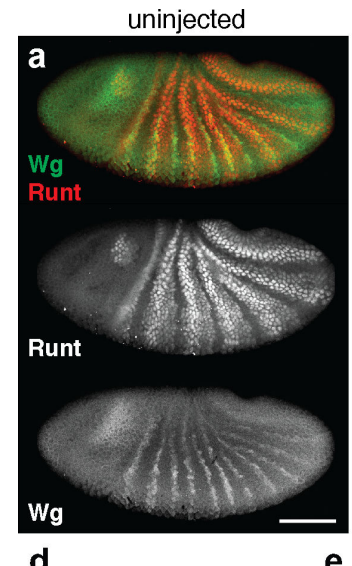

e

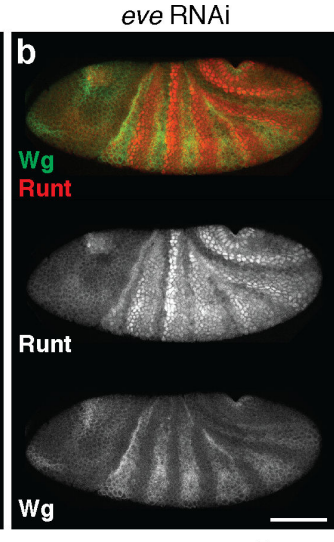

$\mathbf{f}$
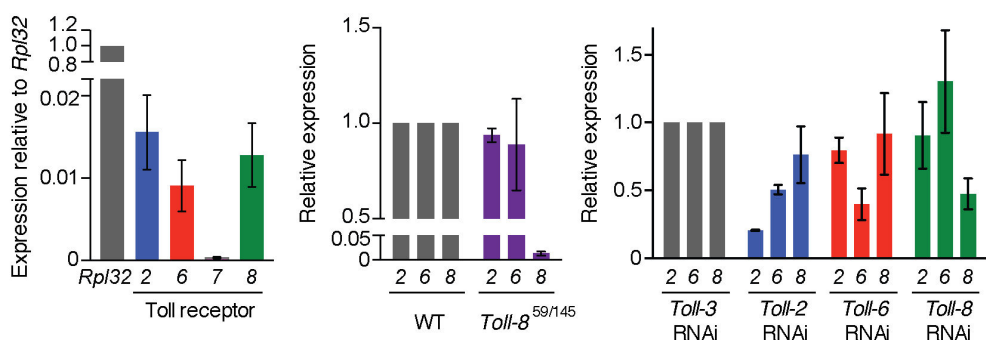

Extended Data Figure 1. Targeting of Eve, Runt, and Toll receptors by dsRNA injection

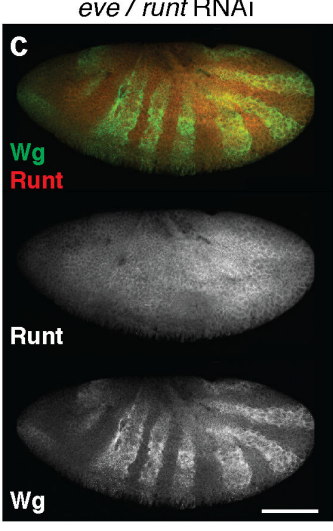


(a-c) Control and dsRNA-injected embryos stained for Runt (red, middle) and Wingless (Wg) (green, bottom) proteins. (a) In uninjected wild-type embryos, Runt is expressed in seven broad stripes and Wg is expressed in 14 narrow stripes. (b) In embryos injected with eve dsRNA alone, Runt is more uniformly expressed, and the Wg expression pattern collapses into fewer, broader stripes, similar to eve mutants (data not shown). (c) In embryos co-injected with eve and runt dsRNAs, Runt protein is undetectable, indicating that the runt dsRNA effectively inhibits Runt expression, and the Wg expression pattern collapses into fewer, broader stripes, similar to eve and runt mutants (data not shown). Anterior left, ventral down. Bars, $100 \mu \mathrm{m}$. (d-f) Quantitative RT-PCR analysis of Toll-2(2), Toll-6(6), Toll-7(7), and Toll- $8(8)$ expression in late stage 6 embryos before axis elongation. $\mathrm{C}_{\mathrm{T}}$ values were normalized to the internal control gene Rpl32. (d) Relative transcript levels in WT embryos were calculated using the $2^{-\Delta \mathrm{CT}}$ method. Toll-2, Toll-6, and Toll- 8 were expressed at comparable levels, whereas Toll-7 was expressed at much lower levels. (e) Toll- 8 expression in Toll- $8^{59 / 145}$ embryos was reduced 76-fold compared with WT embryos. (f) Gene expression was specifically reduced in embryos injected with single dsRNAs targeting Toll-2, Toll-6, or Toll- 8 compared with embryos injected with a control Toll-3 dsRNA, as determined using the $2^{-\Delta \Delta \mathrm{CT}}$ method.
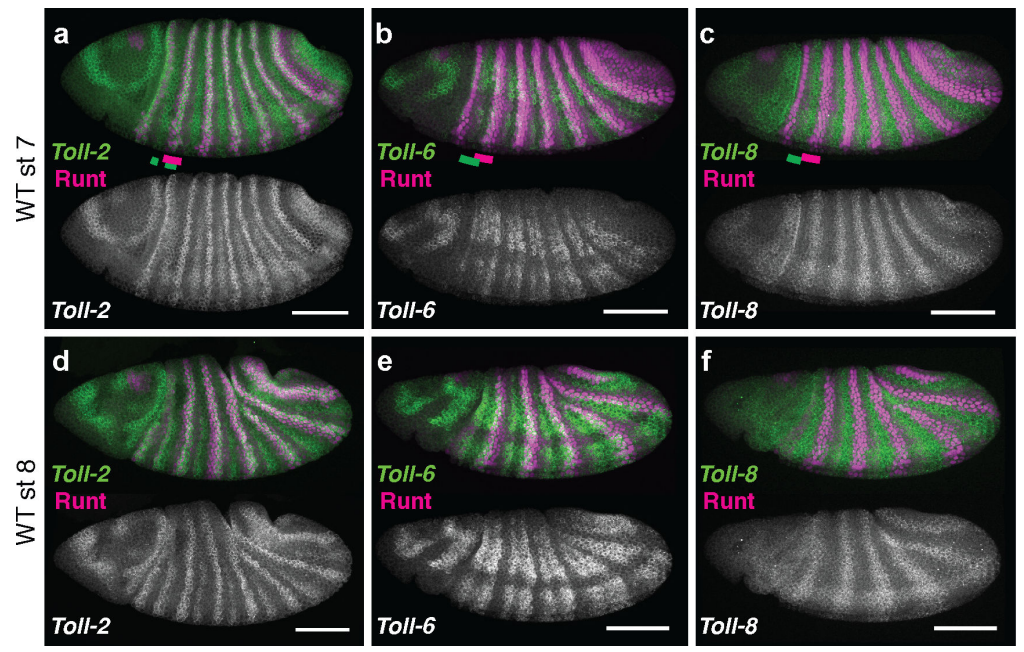

Extended Data Figure 2. Expression patterns of Toll-2, Toll-6, and Toll-8 relative to Runt (a-f) Toll-2, Toll-6, and Toll- 8 transcripts (green top, white bottom) and Runt protein (magenta) in wild-type (WT) embryos during early (stage 7, a-c) and mid-elongation (stage 8, d-f). The embryos are the same as in Fig. 1a-f. Colored bars indicate the position of the Toll-2, Toll-6, and Toll-8 stripes (green) relative to Runt. Anterior left, ventral down. Bars, $100 \mu \mathrm{m}$. 

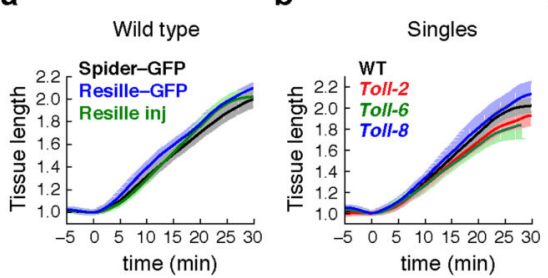

$\overline{\bar{\Phi}} \begin{gathered}\text { Spider-GFP } \\ \text { 2.0 }\end{gathered}$

1.6 Resille inj

으 1.2

के 0.8

일 0.4

흘

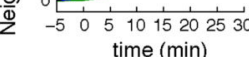

$\overline{\bar{\Phi}} 1.6$ Spider-GFP

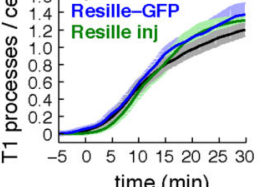

time (min)
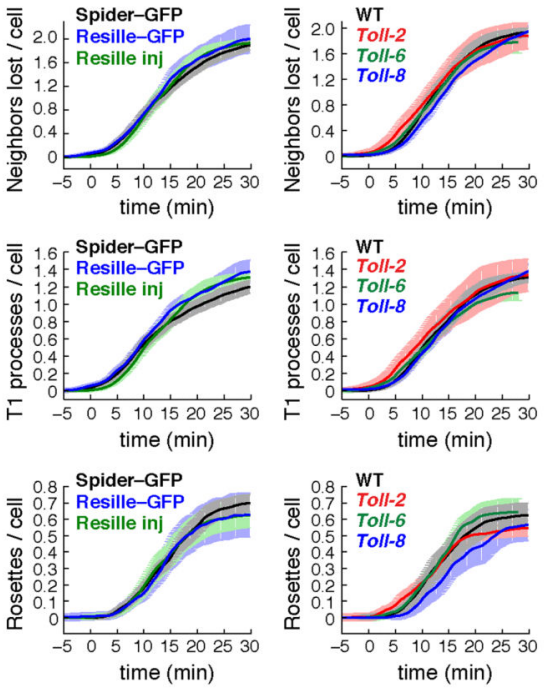

f

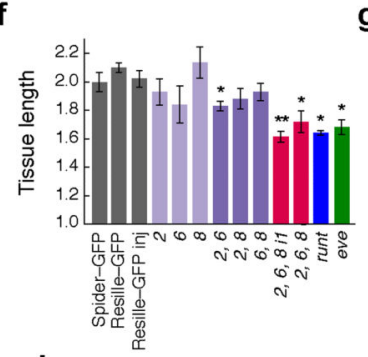

j

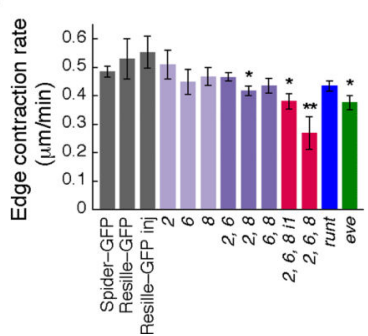

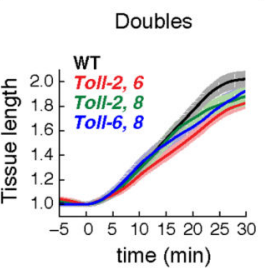

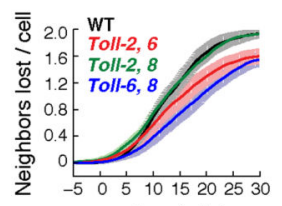

time (min)
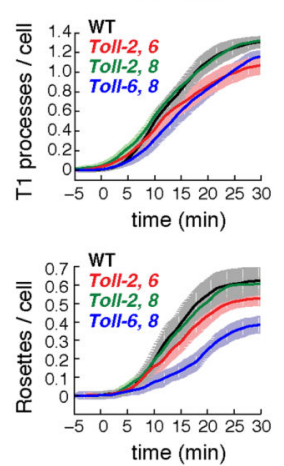

d
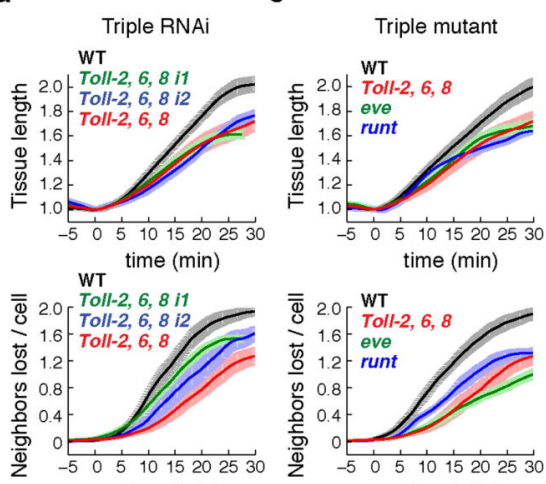

T
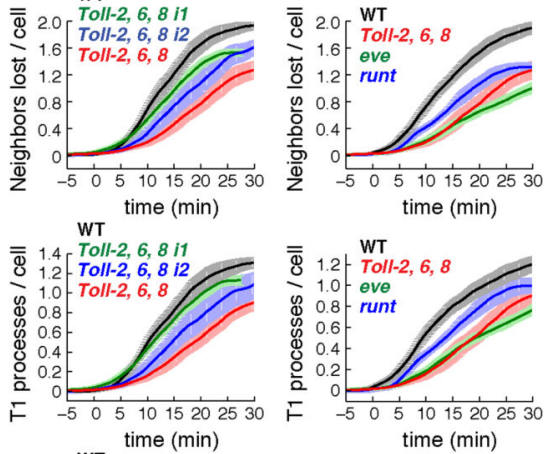

time (min)
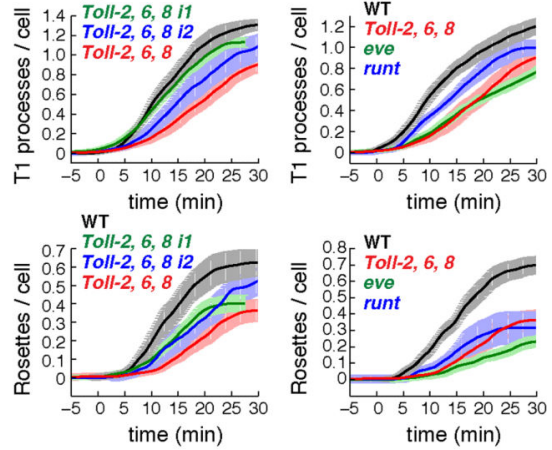

time (min)

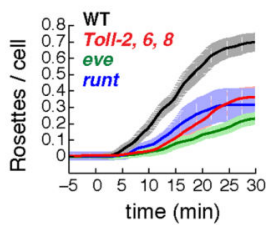

g

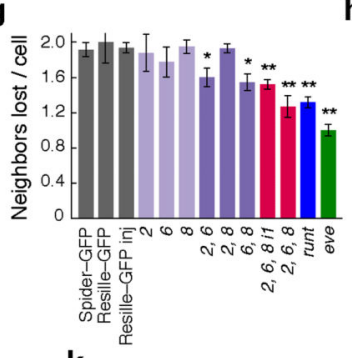

k

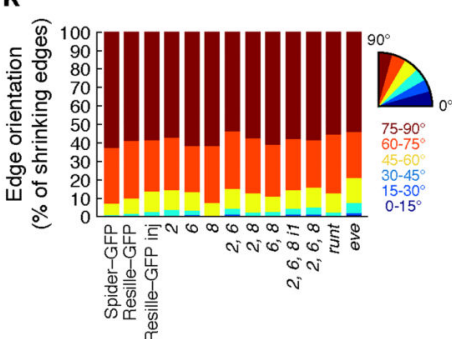

h
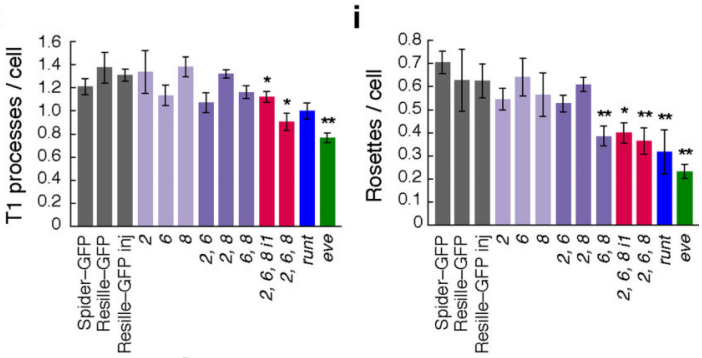

I

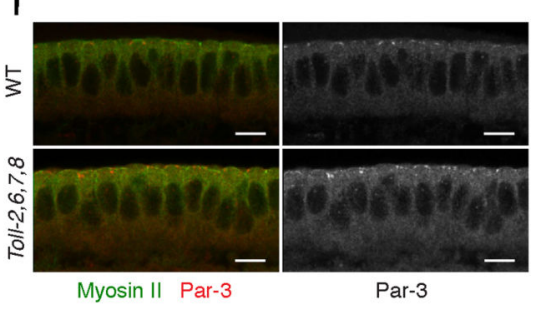

Extended Data Figure 3. Time-lapse imaging of embryos defective for combinations of Toll-2, Toll-6, and Toll-8

(a-e) Axis elongation (tissue AP length relative to $\mathrm{t}=0$ ) (top row), total cell rearrangements (average number of neighbors lost per cell) (second row), T1 processes resulting from the contraction of single edges ${ }^{7}$ (third row), and rosette rearrangements resulting from the contraction of multiple connected edges ${ }^{8}$ (fourth row) over time in wild-type embryos (a) and embryos defective for one (b), two (c), or three (d,e) Toll receptors. Images were acquired every $15 \mathrm{~s}$. (f-i) Axis elongation (f), average number of cell rearrangements (g), T1 processes (h), and rosettes (i) per cell at $\mathrm{t}=30 \mathrm{~min}$. (j) Edge contraction rate for AP edges 
(oriented $75-90^{\circ}$ relative to the AP axis) at mid-stage 7 (averaged from $\mathrm{t}=5-8 \mathrm{~min}$ after the onset of elongation). (k) The orientation of shrinking edges relative to the AP axis $\left(0^{\circ}\right)$ was similar for all conditions. Single average values were obtained for each embryo, and plots show the mean \pm s.e.m. across embryos. ${ }^{*} p=0.01-0.03$, $* * p<0.005$ (unpaired t-test). $\mathrm{n}=3-8$ embryos/genotype, 164-365 cells/embryo (see Supplementary Table 2 for full list of $n$ values). (l) Cross sections of the ventrolateral epithelium in wild-type and Toll-2 ${ }^{276}$, Toll- $6^{\mathrm{B}}$, Toll- $7^{14 \mathrm{~F}}$, Toll- $8^{59}$ mutant (Toll-2,6,7,8) embryos, showing that apical-basal polarity is unaffected in quadruple mutants. Myosin II (green) and Par-3 (red, white) are enriched at apical adherens junctions. Apical up, basal down. Bars, $10 \mu \mathrm{m}$. WT (Spider-GFP in a, e-k; Resille-GFP in a, f-k; and Resille-GFP+Toll-3 dsRNA in a-d and f-k); Toll-2 (Resille-GFP+Toll-2 dsRNA); Toll-6 (Resille-GFP+Toll-6dsRNA); Toll-8 (Resille-GFP; Toll-859/145); Toll-2,6(Resille-GFP+Toll-2/Toll-6 dsRNAs); Toll-2,8 (Resille-GFP; Toll- $8^{59 / 145}+$ Toll-2 dsRNA); Toll-6,8 (Toll-2 $2^{476} / C y O$; Toll- $8^{59}$, Toll- $6^{5 \mathrm{~A}}$, Spider-GFP); Toll-2,6,8 (Toll-2 $2^{\Delta 76}$; Toll- $8^{59}$, Toll- $\sigma^{\mathrm{A}}$, Spider-GFP), Toll-2,6,8 11 (Resille-GFP; Toll- $8^{59 / 145}+$ Toll-2/ Toll-6 dsRNAs set 1); Toll-2,6,8 i2 (Resille-GFP; Toll- $8^{59 / 145}+$ Toll-2l Toll-6 dsRNAs set 2); runt (runt ${ }^{\mathrm{LB} 5}$; Spider-GFP/+); and eve (eve ${ }^{\mathrm{R} 13}$; Spider-GFP/+). 
a

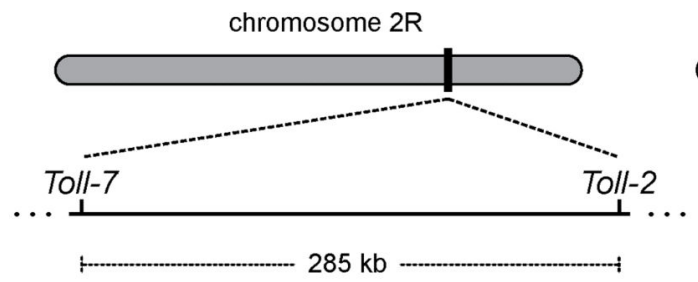

Toll-2/+ ; Toll-8, Toll-6/+ males and females

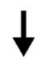

1 out of 16 progeny lack three TLR genes
Toll-2, Toll-7/+ ; Toll-8, Toll-6/+ males and females

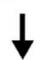

1 out of 16 progeny lack four TLR genes

b

TALEN-induced Toll-6 frameshift mutations on Toll-8 ${ }^{59}$ chromosome III

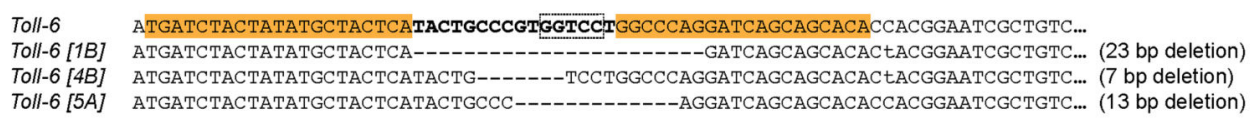

Predicted amino-acid sequences of mutant Toll-6 proteins

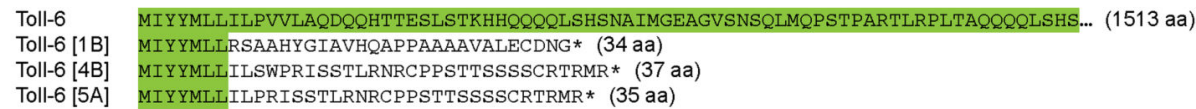

C

TALEN-induced Toll-7 frameshift mutations on Toll-2 ${ }^{476}$ chromosome II Deletions

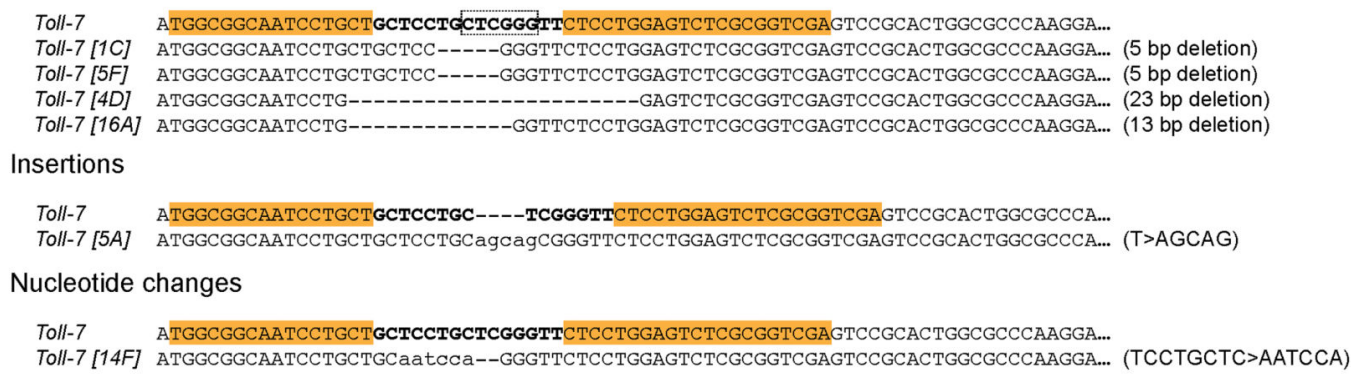

\section{Predicted amino-acid sequences of mutant Toll-7 proteins}

Toll-7 MAAILLLLLGFSWSLAVESALAPKESESSASAMLGAGTGAAATVSLSGDYSSLLSNVPAASPVPANPSQPSGPANQCSWSYNGTSSVHCALRL... (1446 aa) Toll-7 [1C] MAAILLLRVLLESRGRVRTGAQGERIECQRHVRRRNRRCHSIAIRRLLLAAVQCAGRLAGSGQSIATQWPGQPVLLVLQRHQFGALRPASH* (92 aa) Toll-7 [4D] MAAILESRGRVRTGAQGERIECQRHVRRRNRSRCHSIAIRRLLLAAVQCAGRLAGSGQSIATQWPGQPVLLVLQRHQFGALRPASH* (86 aa) Toll-7 [5A] MAAILLLLQQRVLLESRGRVRTGAQGERIECQRHVRRRNRSRCHSIAIRRLLLAAVQCAGRLAGSGQSIATQWPGQPVLLVLQRHQFGALRPASH* (95 aa) Toll-7 [5F] MAAILLLRVLLESRGRVRTGAOGERIECQRHVRRRNRSRCHSIAIRRLLLAAVQCAGRLAGSGQSIATQWPGQPVLLVLQRHQFGALRPASH* (92 aa) Toll-7 [14F] MAAILLQSRVLLESRGRVRTGAQGERIECQRHVRRRNRSRCHSIAIRRLLLAAVQCAGRLAGSGQSIATQWPGQPVLLVLQRHQF GALRPASH* (93 aa) Toll-7 [16A] MAAILGSPGVSRSSPHWRPRRANRVPAPC* (29 aa)

Extended Data Figure 4. Generation of double, triple, and quadruple Toll receptor mutants (a) The crossing strategy used to generate Toll-2,6,8 triple mutants and Toll-2,6,7,8 quadruple mutants. Toll- 7 and Toll-2 are $285 \mathrm{~kb}$ apart on the right arm of chromosome II and Toll- 8 and Toll- 6 are $94 \mathrm{~kb}$ apart on the left arm of chromosome III. (b) Three unique Toll-6 null alleles (Toll- $\sigma^{\mathrm{B}}$, Toll- $\sigma^{4 \mathrm{~B}}$, and Toll- $\sigma^{\mathrm{A}}$ ) were generated on the Toll- $8^{59}$ chromosome using TALEN-mediated mutagenesis to create Toll- 8 , Toll- 6 double-mutant chromosomes. (c) Six unique Toll-7 null alleles (Toll-71C, Toll- $7^{4 \mathrm{D}}$, Toll- $7 \mathrm{AA}$, Toll- $-5 \mathrm{~F}$, Toll- $7^{14 \mathrm{~F}}$, and Toll- $7^{16 \mathrm{~A}}$ ) were generated on the Toll-2 $2^{\Delta 76}$ chromosome using TALEN-mediated 
mutagenesis to create Toll-7, Toll-2 double-mutant chromosomes. Each Toll-6 and Toll- 7 allele is a frame-shift mutation leading to premature translational termination. TALENs were designed to induce double-stranded breaks immediately downstream of the ATG translational start sites. Orange letters indicate the TALEN binding sites, and the spacer regions are shown in bold. The Ava II and Ava Irestriction sites used for screening are indicated with dotted boxes. Shown below are the predicted amino acid sequences of the mutant proteins compared with the wild-type sequence. Residues that are identical in the mutant and wild-type proteins are shown in green. 


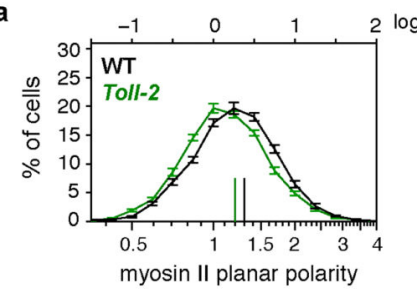

c

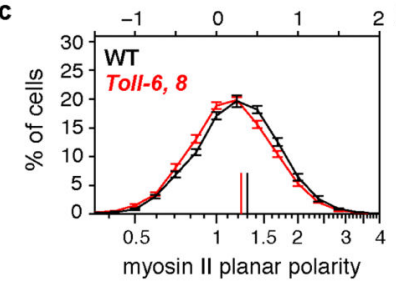

e

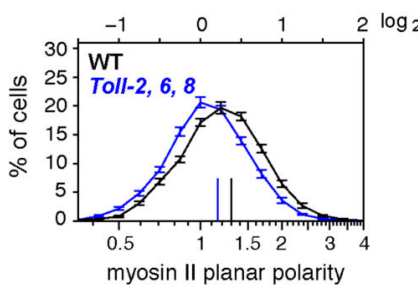

g
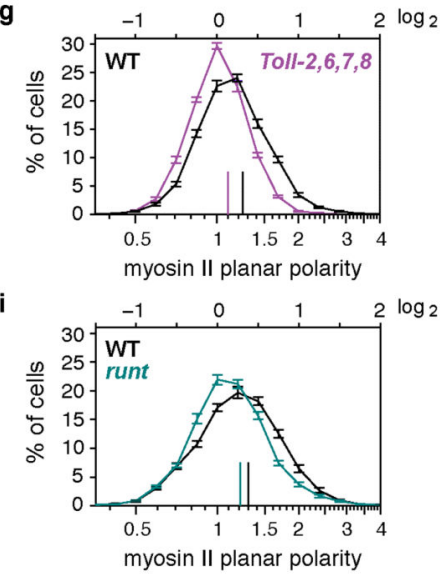

k

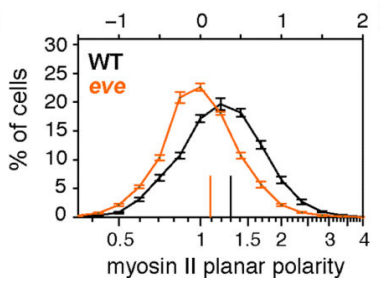

b

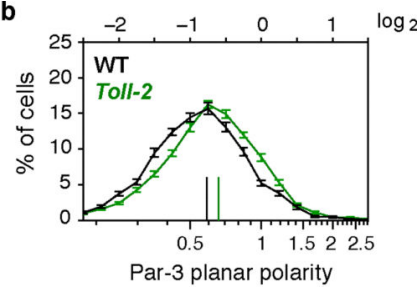

d
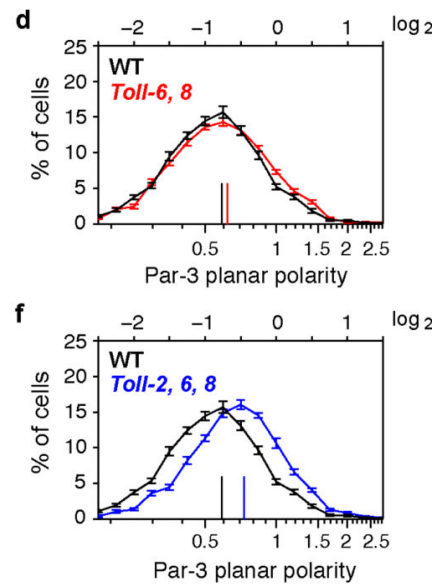

h
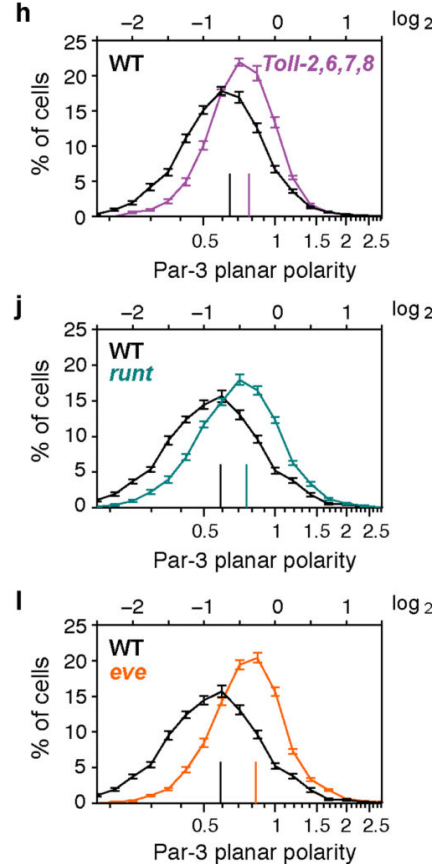

Extended Data Figure 5. Distributions of cell polarity measurements in Toll receptor mutants (a-l) Planar polarity distributions for myosin II (left panels) and Par-3 (right panels) in Toll-2 single mutants (a,b), Toll-6,8 double mutants (c,d), Toll-2,6,8 triple mutants (e,f), Toll-2,6, 7,8 quadruple mutants (g,h), runt mutants (i,j), and eve mutants (k,l). Vertical lines indicate the means of the distributions. Error bars indicate s.e.m. between embryos. Mean planar polarity was shifted toward 1 (absolute ratio; 0 on the $\log _{2}$ scale) in Toll-2 single mutants ( $p=0.005$ for myosin and $p<0.00005$ for Par-3), Toll-2,6,8 triple mutants $(p<0.00002$ for myosin and Par-3), Toll-2,6,7,8 quadruple mutants ( $p<0.00001$ for myosin and Par-3), 
runt mutants ( $p=0.002$ for myosin and $p<0.00001$ for Par-3), and eve mutants ( $p<0.00001$ for myosin and Par-3), indicating reduced planar polarity (unpaired t-test with the means of the distributions used as the test statistic). Planar polarity in Toll-2,6,7,8 quadruple mutants was not significantly enhanced relative to triple mutants. Single values were obtained for each embryo, and plots show the mean \pm s.e.m. across embryos. $n=2,166-4,909$ cells in 7-20 embryos/genotype (see Supplementary Table 2).
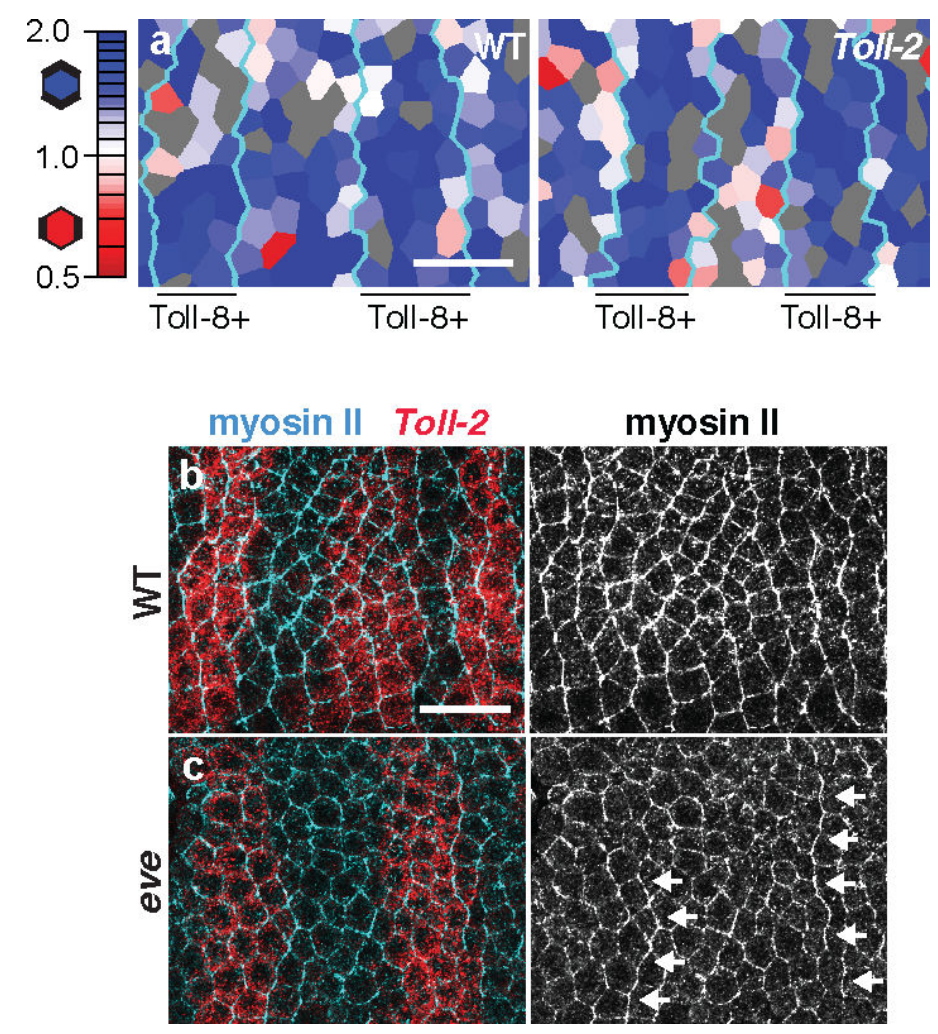

Extended Data Figure 6. Toll receptor expression affects planar polarity in a regional manner (a) Single-cell analysis of Par-3 planar polarity in wild-type (WT) (left) and Toll-2 mutant (right) embryos. Toll-8-expressing cells were identified by fluorescence in situ hybridization. Cyan lines, boundaries between stripes; Toll-8+, Toll-8-expressing cells. AP enriched (red), DV enriched (blue). Cells without at least one AP and one DV edge were not scored (gray). (b,c) Myosin II (cyan, white) and Toll-2 mRNA (red) in stage 7 WT (b) and eve mutant (c) embryos. Arrows, residual myosin cables in eve embryos. Anterior left, ventral down. Bars, $20 \mu \mathrm{m}$.

\section{Supplementary Material}

Refer to Web version on PubMed Central for supplementary material.

\section{Acknowledgments}

We thank Kathryn Anderson, Karen Kasza, Will Razzell, Germán Sabio, Mimi Shirasu-Hiza, Alison Spencer, Masako Tamada, and Richard Zallen for comments on the manuscript, Ben Glick for the fast-folding YFP, Mike Buszczak for pUASp-w-attB, and the BAC-Recombineering Core Facility at the University of Chicago for Toll-8- 
YFP. This work was funded by NIH/NIGMS grants GM079340 and GM102803 to J.A.Z. J.A.Z. is an Early Career Scientist of the Howard Hughes Medical Institute.

\section{References}

1. Keller R, et al. Mechanisms of convergence and extension by cell intercalation. Philosophical Transactions of the Royal Society B: Biological Sciences. 2000; 355:897-922.

2. Zallen JA. Planar polarity and tissue morphogenesis. Cell. 2007; 129:1051-1063. [PubMed: 17574020]

3. Wallingford JB. Planar Cell Polarity and the Developmental Control of Cell Behavior in Vertebrate Embryos. Annu. Rev. Cell Dev. Biol. 2012; 28:627-653. [PubMed: 22905955]

4. Solnica-Krezel L, Sepich DS. Gastrulation: making and shaping germ layers. Annu. Rev. Cell Dev. Biol. 2012; 28:687-717. [PubMed: 22804578]

5. Walck-Shannon E, Hardin J. Cell intercalation from top to bottom. Nat Rev Mol Cell Biol. 2014; 15:34-48. [PubMed: 24355988]

6. Zallen JA, Wieschaus E. Patterned gene expression directs bipolar planar polarity in Drosophila. Dev Cell. 2004; 6:343-355. [PubMed: 15030758]

7. Bertet C, Sulak L, Lecuit T. Myosin-dependent junction remodelling controls planar cell intercalation and axis elongation. Nature. 2004; 429:667-671. [PubMed: 15190355]

8. Blankenship JT, Backovic ST, Sanny JSP, Weitz O, Zallen JA. Multicellular rosette formation links planar cell polarity to tissue morphogenesis. Dev Cell. 2006; 11:459-470. [PubMed: 17011486]

9. Rauzi M, Verant P, Lecuit T, Lenne P-F. Nature and anisotropy of cortical forces orienting Drosophila tissue morphogenesis. Nat Cell Biol. 2008; 10:1401-1410. [PubMed: 18978783]

10. Fernández-González R, Simões S. de M. Röper J-C, Eaton S, Zallen JA. Myosin II dynamics are regulated by tension in intercalating cells. Dev Cell. 2009; 17:736-743. [PubMed: 19879198]

11. Nishimura T, Takeichi M. Shroom3-mediated recruitment of Rho kinases to the apical cell junctions regulates epithelial and neuroepithelial planar remodeling. Development. 2008; 135:1493-1502. [PubMed: 18339671]

12. Nishimura T, Honda H, Takeichi M. Planar cell polarity links axes of spatial dynamics in neuraltube closure. Cell. 2012; 149:1084-1097. [PubMed: 22632972]

13. Lienkamp SS, et al. Vertebrate kidney tubules elongate using a planar cell polarity-dependent, rosette-based mechanism of convergent extension. Nat Genet. 2012; 44:1382-1387. [PubMed: 23143599]

14. Mahaffey JP, Grego-Bessa J, Liem KF, Anderson KV. Cofilin and Vangl2 cooperate in the initiation of planar cell polarity in the mouse embryo. Development. 2013 doi:10.1242/dev.085316.

15. Shindo A, Wallingford JB. PCP and Septins Compartmentalize Cortical Actomyosin to Direct Collective Cell Movement. Science. 2014; 343:649-652. [PubMed: 24503851]

16. Williams M, Yen W, Lu X, Sutherland A. Distinct apical and basolateral mechanisms drive planar cell polarity-dependent convergent extension of the mouse neural plate. Dev Cell. 2014; 29:34-46. [PubMed: 24703875]

17. Irvine KD, Wieschaus E. Cell intercalation during Drosophila germband extension and its regulation by pair-rule segmentation genes. Development. 1994; 120:827-841. [PubMed: 7600960]

18. Ninomiya H, Elinson RP, Winklbauer R. Antero-posterior tissue polarity links mesoderm convergent extension to axial patterning. Nature. 2004; 430:364-367. [PubMed: 15254540]

19. St Johnston D, Nüsslein-Volhard C. The origin of pattern and polarity in the Drosophila embryo. Cell. 1992; 68:201-219. [PubMed: 1733499]

20. Butler LC, et al. Cell shape changes indicate a role for extrinsic tensile forces in Drosophila germband extension. Nat Cell Biol. 2009; 11:859-864. [PubMed: 19503074]

21. Simões, S. de M., et al. Rho-kinase directs Bazooka/Par-3 planar polarity during Drosophila axis elongation. Dev Cell. 2010; 19:377-388. [PubMed: 20833361]

22. Wieschaus, E.; Sweeton, D.; Costa, M. Gastrulation. Springer US; 1992. p. 213-223.doi: 10.1007/978-1-4684-6027-8_13 
23. Brennan CA, Anderson KV. Drosophila: The Genetics of Innate Immune Recognition and Response. Annu Rev Immunol. 2004; 22:457-483. [PubMed: 15032585]

24. Janeway CA, Medzhitov R. Innate immune recognition. Annu Rev Immunol. 2002; 20:197-216. [PubMed: 11861602]

25. Leulier F, Lemaitre B. Toll-like receptors - taking an evolutionary approach. Nat Rev Genet. 2008; 9:165-178. [PubMed: 18227810]

26. Kawai T, Akira S. The role of pattern-recognition receptors in innate immunity: update on Toll-like receptors. Nat. Immunol. 2010; 11:373-384. [PubMed: 20404851]

27. Tauszig S, Jouanguy E, Hoffmann JA, Imler JL. Toll-related receptors and the control of antimicrobial peptide expression in Drosophila. Proc Natl Acad Sci USA. 2000; 97:10520-10525. [PubMed: 10973475]

28. Morisato D, Anderson KV. Signaling pathways that establish the dorsal-ventral pattern of the Drosophila embryo. Annu. Rev. Genet. 1995

29. Chiang C, Beachy PA. Expression of a novel Toll-like gene spans the parasegment boundary and contributes to hedgehog function in the adult eye of Drosophila. Mech. Dev. 1994; 47:225-239. [PubMed: 7848870]

30. Kambris Z, Hoffmann JA, Imler J-L, Capovilla M. Tissue and stage-specific expression of the Tolls in Drosophila embryos. Gene Expr Patterns. 2002; 2:311-317. [PubMed: 12617819]

31. Eldon E, et al. The Drosophila 18 wheeler is required for morphogenesis and has striking similarities to Toll. Development. 1994; 120:885-899. [PubMed: 7600965]

32. Keith FJ, Gay NJ. The Drosophila membrane receptor Toll can function to promote cellular adhesion. EMBO J. 1990; 9:4299-4306. [PubMed: 2124970]

33. Kim S, Chung S, Yoon J, Choi K-W, Yim J. Ectopic expression of Tollo/Toll-8 antagonizes Dpp signaling and induces cell sorting in the Drosophila wing. Genesis. 2006; 44:541-549. [PubMed: 17078066]

34. Kleve CD, Siler DA, Syed SK, Eldon ED. Expression of 18-wheeler in the follicle cell epithelium affects cell migration and egg morphology in Drosophila. Dev Dyn. 2006; 235:1953-1961. [PubMed: 16607637]

35. Kolesnikov T, Beckendorf SK. 18 wheeler regulates apical constriction of salivary gland cells via the Rho-GTPase-signaling pathway. Dev Biol. 2007; 307:53-61. [PubMed: 17512518]

36. Paré A, et al. Visualization of individual Scr mRNAs during Drosophila embryogenesis yields evidence for transcriptional bursting. Curr Biol. 2009; 19:2037-2042. [PubMed: 19931455]

37. Cermak T, et al. Efficient design and assembly of custom TALEN and other TAL effector-based constructs for DNA targeting. Nucleic Acids Res. 2011; 39:e82. [PubMed: 21493687]

38. Tamada M, Farrell DL, Zallen JA. Abl Regulates Planar Polarized Junctional Dynamics through $\beta$ Catenin Tyrosine Phosphorylation. Dev Cell. 2012; 22:309-319. [PubMed: 22340496]

39. Kasza KE, Farrell DL, Zallen JA. Spatiotemporal control of epithelial remodeling by regulated myosin phosphorylation. PNAS. 2014; 111:11732-11737. [PubMed: 25071215]

40. McIlroy G, et al. Toll-6 and Toll-7 function as neurotrophin receptors in the Drosophila melanogaster CNS. Nat. Neurosci. 2013; 16:1248-1256. [PubMed: 23892553]

41. Ballard SL, Miller DL, Ganetzky B. Retrograde neurotrophin signaling through Tollo regulates synaptic growth in Drosophila. J. Cell Biol. 2014; 204:1157-1172. [PubMed: 24662564]

42. Özkan E, et al. An Extracellular Interactome of Immunoglobulin and LRR Proteins Reveals Receptor-Ligand Networks. Cell. 2013; 154:228-239. [PubMed: 23827685]

43. de Wit J, Hong W, Luo L, Ghosh A. Role of leucine-rich repeat proteins in the development and function of neural circuits. Annu. Rev. Cell Dev. Biol. 2011; 27:697-729. [PubMed: 21740233]

44. Rakoff-Nahoum S, Medzhitov R. Toll-like receptors and cancer. Nat Rev Cancer. 2008; 9:57-63. [PubMed: 19052556]

45. Grote K, Schütt H, Schieffer B. Toll-Like Receptors in Angiogenesis. The Scientific World JOURNAL. 2011; 11:981-991. [PubMed: 21516292]

46. Huebener P, Schwabe RF. Regulation of wound healing and organ fibrosis by toll- like receptors. Biochimica et Biophysica Acta (BBA) - Molecular Basis of Disease. 2013; 1832:1005-1017. [PubMed: 23220258] 
47. West MA, et al. Enhanced dendritic cell antigen capture via toll-like receptor-induced actin remodeling. Science. 2004; 305:1153-1157. [PubMed: 15326355]

48. Ma Y, et al. Toll-like receptor 8 functions as a negative regulator of neurite outgrowth and inducer of neuronal apoptosis. J. Cell Biol. 2006; 175:209-215. [PubMed: 17060494]

49. Cameron JS, et al. Toll-like receptor 3 is a potent negative regulator of axonal growth in mammals. J Neurosci. 2007; 27:13033-13041. [PubMed: 18032677]

50. Rose D, et al. Toll, a muscle cell surface molecule, locally inhibits synaptic initiation of the RP3 motoneuron growth cone in Drosophila. Development. 1997; 124:1561-1571. [PubMed: 9108372]

51. Gerttula S, Jin Y, Anderson KV. Zygotic expression and activity of the Drosophila Toll gene, a gene required maternally for embryonic dorsal-ventral pattern formation. Genetics. 1988; 119:123-133. [PubMed: 2456252]

52. Yagi Y, Nishida Y, Ip YT. Functional analysis of Toll-related genes in Drosophila. Dev. Growth Differ. 2010; 52:771-783. [PubMed: 21158756]

53. Nüsslein-Volhard C, Wieschaus E. Mutations affecting segment number and polarity in Drosophila. Nature. 1980; 287:795-801. [PubMed: 6776413]

54. Duffy JB, Gergen JP. The Drosophila segmentation gene runt acts as a position-specific numerator element necessary for the uniform expression of the sex-determining gene Sex-lethal. Genes Dev. 1991; 5:2176-2187. [PubMed: 1748277]

55. Ludwig MZ, Manu, Kittler R, White KP, Kreitman M. Consequences of eukaryotic enhancer architecture for gene expression dynamics, development, and fitness. PLoS Genet. 2011; 7:e1002364. [PubMed: 22102826]

56. Martin AC, Gelbart M, Fernández-González R, Kaschube M, Wieschaus EF. Integration of contractile forces during tissue invagination. J. Cell Biol. 2010; 188:735-749. [PubMed: 20194639]

57. Royou A, Field C, Sisson JC, Sullivan W, Karess R. Reassessing the role and dynamics of nonmuscle myosin II during furrow formation in early Drosophila embryos. Mol. Biol. Cell. 2004; 15:838-850. [PubMed: 14657248]

58. Schmittgen TD, Livak KJ. Analyzing real-time PCR data by the comparative C(T) method. Nat Protoc. 2008; 3:1101-1108. [PubMed: 18546601]

59. Nagaso H, Murata T, Day N, Yokoyama KK. Simultaneous detection of RNA and protein by in situ hybridization and immunological staining. J. Histochem. Cytochem. 2001; 49:1177-1182. [PubMed: 11511686]

60. Kosman D, et al. Multiplex detection of RNA expression in Drosophila embryos. Science. 2004; 305:846. [PubMed: 15297669]

61. Kosman D, Small S, Reinitz J. Rapid preparation of a panel of polyclonal antibodies to Drosophila segmentation proteins. Dev Genes Evol. 1998; 208:290-294. [PubMed: 9683745]

62. Hutson MS, et al. Forces for morphogenesis investigated with laser microsurgery and quantitative modeling. Science. 2003; 300:145-149. [PubMed: 12574496] 

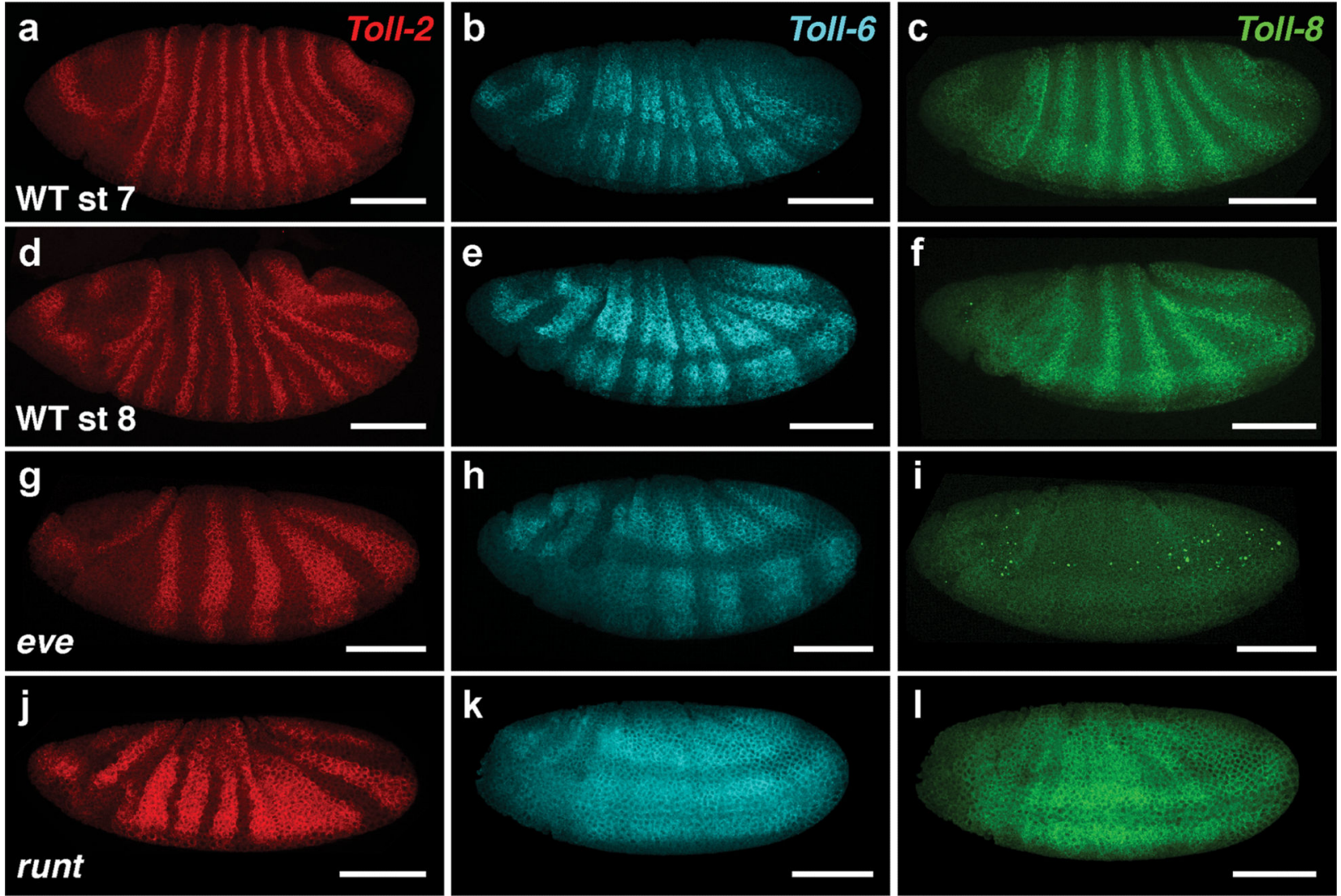

i

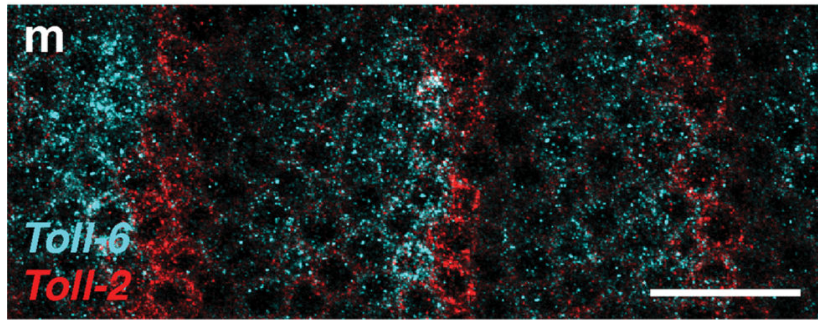

n.

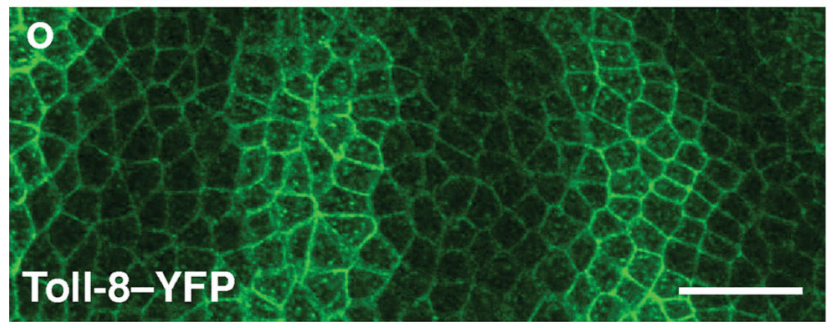

\section{TOII-8 \\ (2) 2}

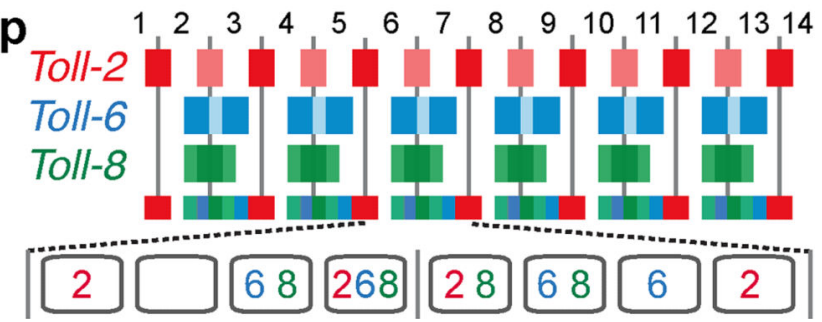

Figure 1. Cells express different combinations of Toll-2, Toll-6, and Toll-8 along the anteriorposterior axis

(a-n) Toll-2 (red), Toll-6 (cyan), and Toll-8 (green) mRNA expression in wild-type (WT) (a$\mathrm{f}, \mathrm{m}, \mathrm{n})$, eve mutant ( $\mathrm{g}-\mathrm{i})$, and runt mutant (j-1) embryos during early (stage 7 , a-c,m,n) and mid-elongation (stage 8, d-1). (m,n) Toll-6 (cyan) is expressed anterior to the strong Toll-2 stripes (red) and Toll- 8 (green) is expressed between them. (o) Toll-8-YFP protein in a stage 7 Toll-8 mutant. (p) Schematic of Toll-2, Toll-6, and Toll-8 expression. Numbers, parasegments; vertical lines, parasegmental boundaries. Anterior left, ventral down. Bars, $100 \mu \mathrm{m}(\mathrm{a}-1), 20 \mu \mathrm{m}$ (m-o). 
a

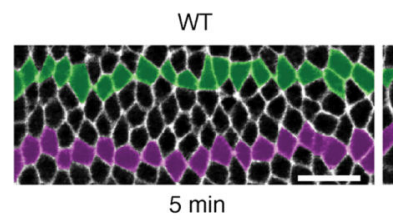

Toll-2, 6, 8

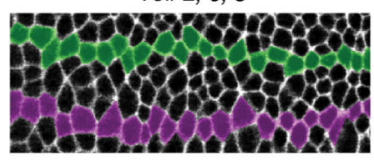

$5 \mathrm{~min}$

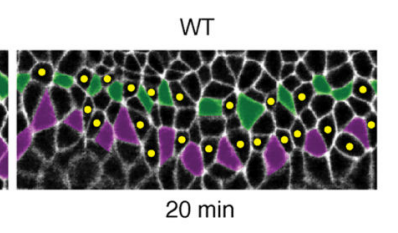

Toll-2, 6, 8

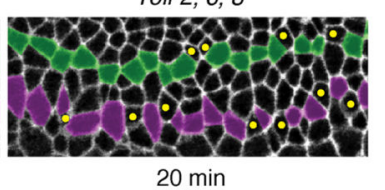

b

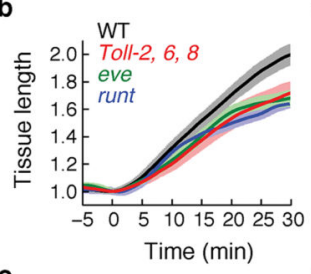

e

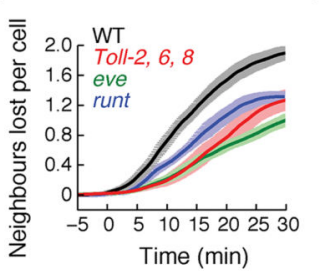

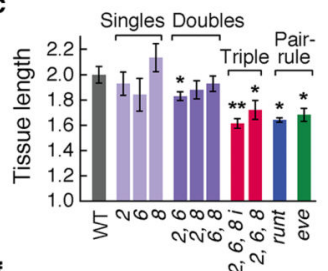

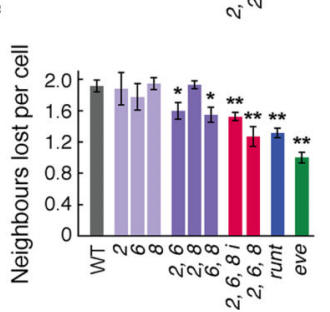

Correctly oriented Y $\rightarrow X \rightarrow Y$ Incorrectly oriented $X \rightarrow X \rightarrow X$ $\begin{array}{cr}\text { Edge } & \text { Edge } \\ \text { contraction } & \text { formation }\end{array}$

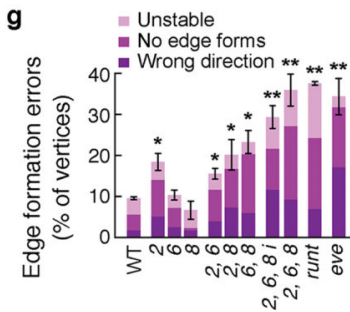

Figure 2. Toll-2, Toll-6, and Toll-8 regulate cell intercalation and axis elongation (a) Stills from time-lapse movies of a wild-type (WT) embryo (top) and a Toll- 8 mutant injected with Toll-2 and Toll-6 dsRNAs (Toll-2,6,8) (bottom). Resille-GFP (white). $\mathrm{t}=0$, onset of elongation. In WT, nearly all initially adjacent cells become separated by intercalated cells (yellow dots). In Toll-2,6,8 embryos, many cells fail to separate. Anterior left, ventral down. Bar, $20 \mu \mathrm{m}$. (b,c) Axis elongation (tissue AP length relative to $t=0$ ) over time (b) and at $30 \mathrm{~min}$ (c). (d) Edge contraction and formation. (e,f) Cell rearrangements over time (e) and at $30 \mathrm{~min}$ (f). Single average values were obtained for each embryo; plots show the mean \pm s.e.m. across embryos. (b-f) n=3-8 embryos/genotype, 164-365 cells/ embryo (Supplementary Table 2). (g) Edge formation errors. n=3-9 embryos/genotype, 42-104 vertices/embryo. ${ }^{*} p=0.01-0.03,{ }^{* *} p<0.005$ (unpaired t-test). WT (Spider-GFP); 2 (Resille-GFP+Toll-2 dsRNA); 6 (Resille-GFP+Toll-6 dsRNA); 8 (Resille-GFP; Toll-8 $8^{59 / 145}$ ); 2,6 (Resille-GFP+Toll-2/ Toll-6 dsRNAs); 2,8 (Resille-GFP; Toll- - $^{59 / 145}+$ Toll-2 dsRNA); 6,8 (Toll-2 $2^{\Delta 76} / C y O$; Toll- $8^{59}$, Toll- $\sigma^{5 \mathrm{~A}}$, Spider-GFP); 2,6,8 i (Resille-GFP; Toll- $8^{59 / 145}+$ Toll-2/Toll-6 dsRNAs); 2,6,8 (Toll-2 ${ }^{276} ;$ Toll- $8^{59}$, Toll- ${ }^{5 \mathrm{~A}}$, Spider-GFP); runt (runt ${ }^{\mathrm{LB} 5}$; Spider-GFP/+); eve (eve ${ }^{\mathrm{R} 13}$; Spider-GFP/+). 

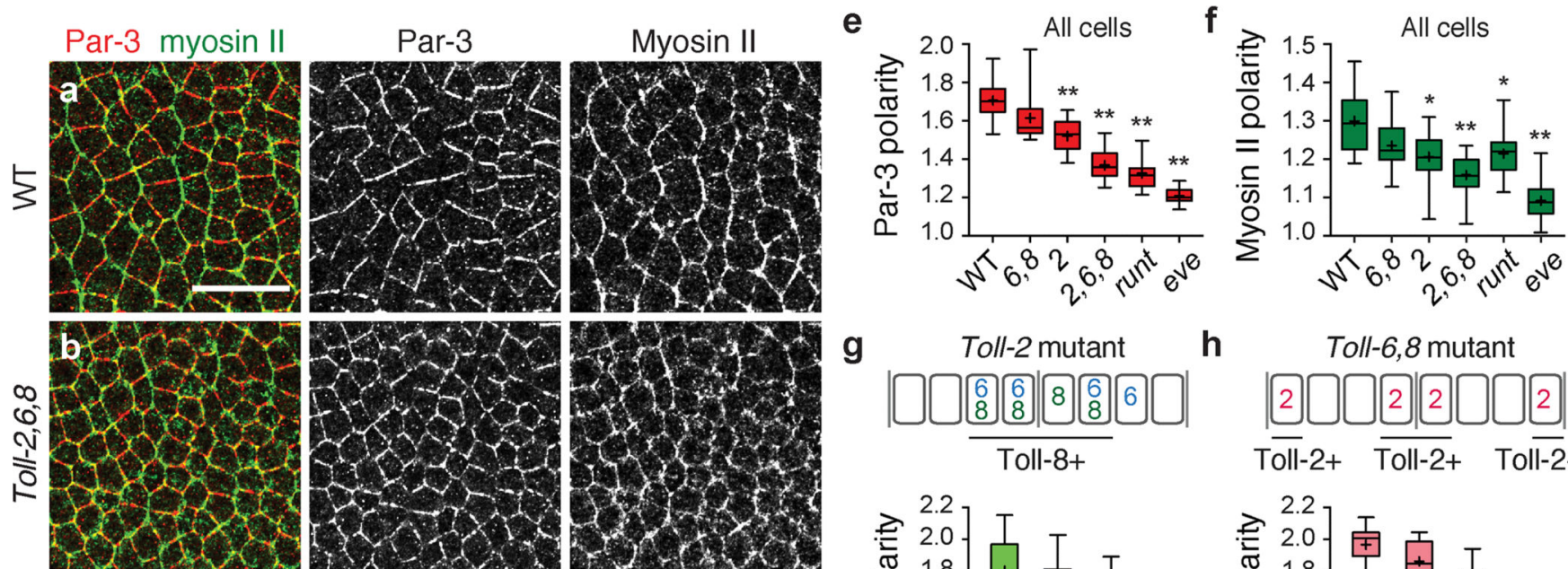

g

Toll-2 mutant $\quad \mathbf{h}$

h Toll-6,8 mutant
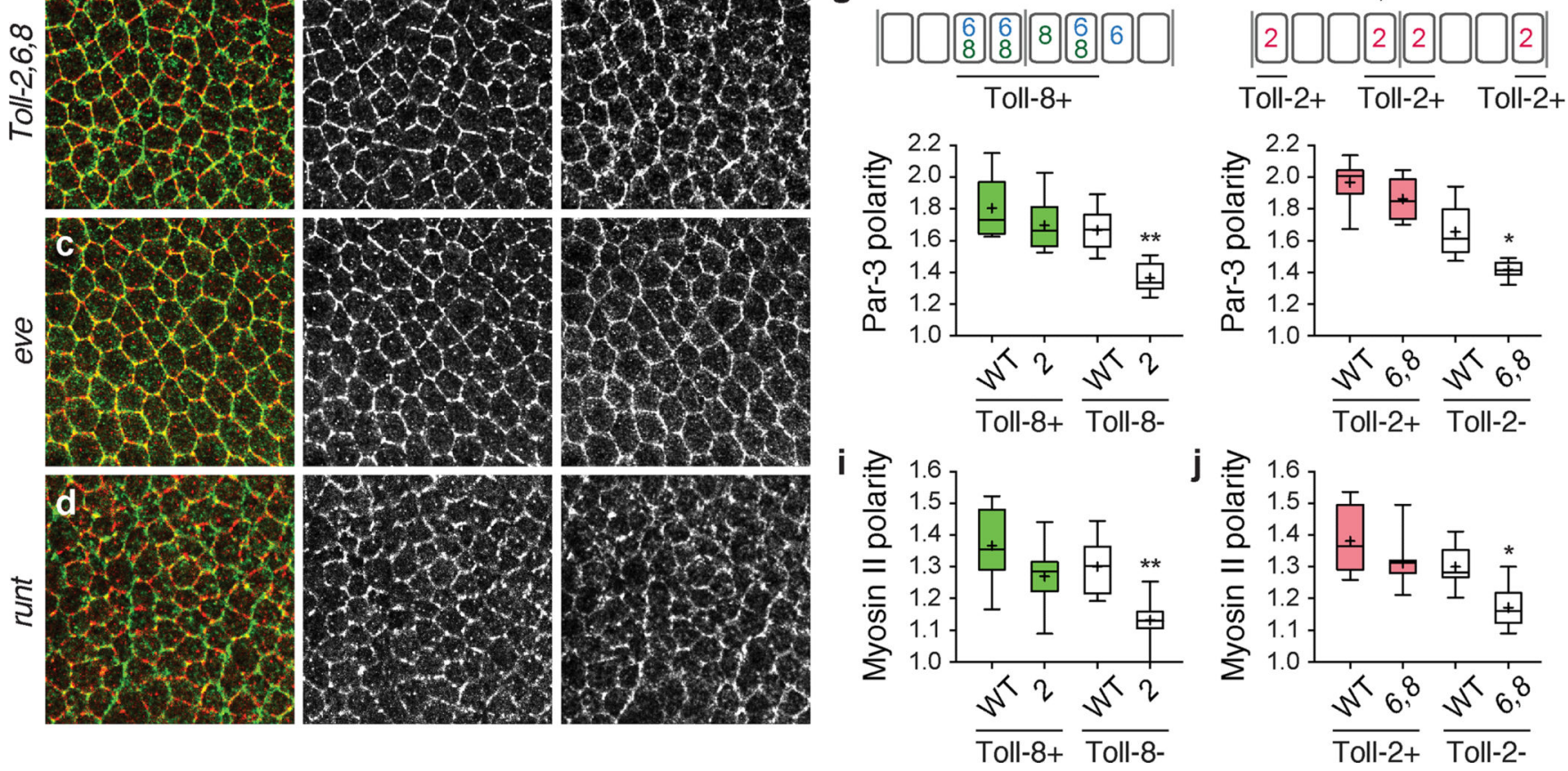

Figure 3. Toll receptors are required for myosin II and Par-3 planar polarity

(a-d) Stage 7 wild-type (WT) (a), Toll-2,6,8 (b), eve (c), and runt (d) embryos. Par-3 (red, middle), myosin II (green, right). (e-j) Par-3 and myosin II planar polarity in all cells (e,f) and subsets of cells (g-j). Horizontal line, median; +, mean; boxes, $2^{\text {nd }}$ and $3^{\text {rd }}$ quartiles; whiskers, $5^{\text {th }}$ to $95^{\text {th }}$ percentile. Single average values were obtained for each embryo; plots show the distribution of values across embryos. ${ }^{*} p \unlhd 0.005,{ }^{* *} p<0.0001$ (unpaired t-test). $\mathrm{n}=$ 2,445-4,698 cells in 11-19 embryos/genotype (Supplementary Table 2). Anterior left, ventral down. Bar, $20 \mu \mathrm{m}$. 


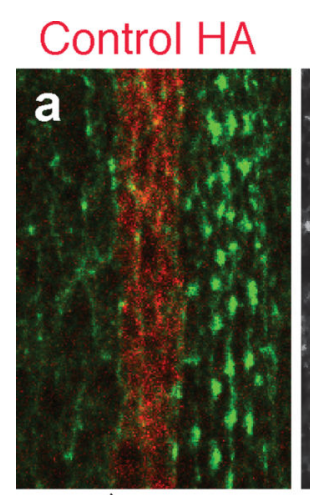

$\uparrow$

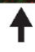

d

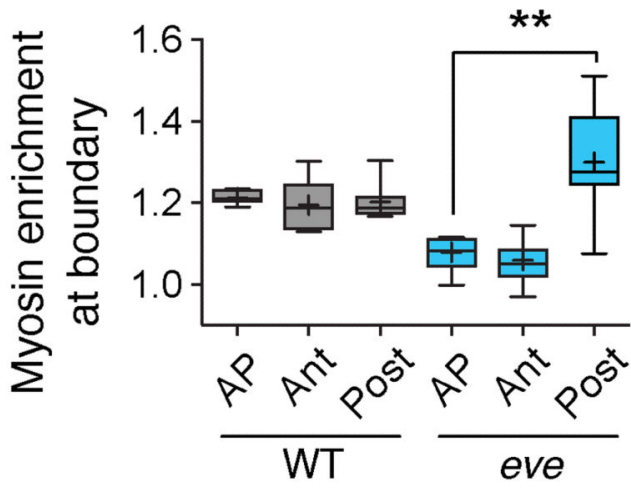

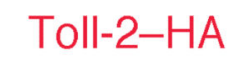

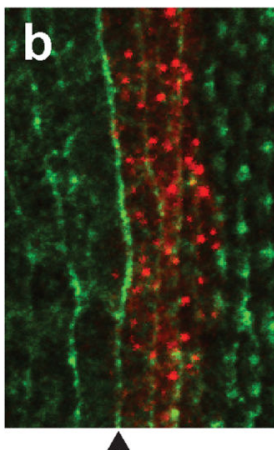

$\uparrow$

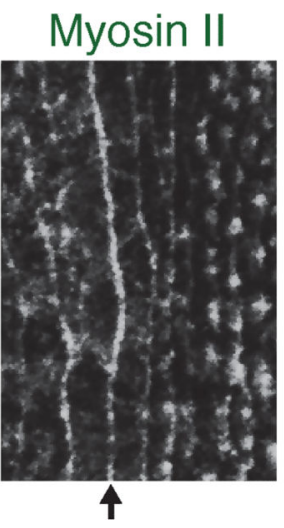

e

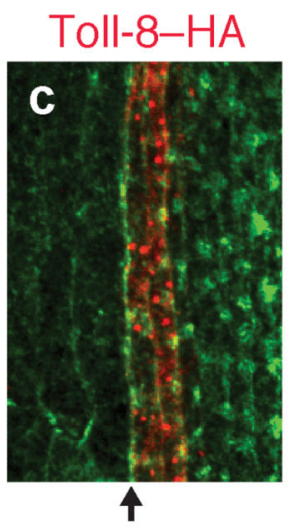

Myosin II

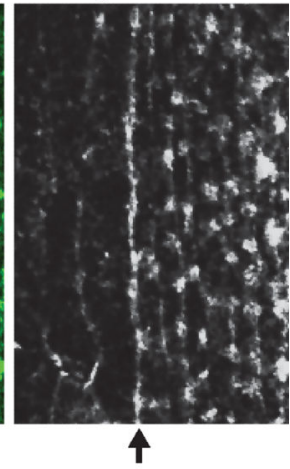

f

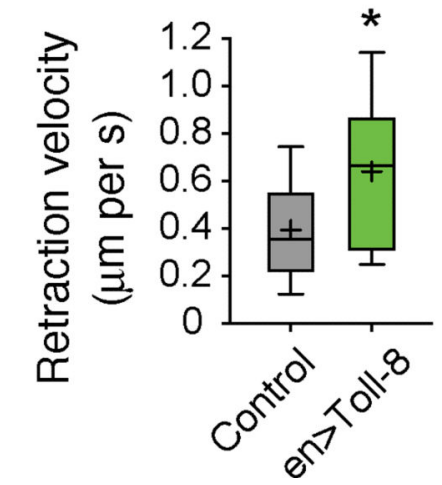

Figure 4. Myosin II localization and activity are enhanced at boundaries of Toll-2 and Toll-8 expression

(a-c) Stage 15 embryos expressing control $\beta$-catenin-HA (a), Toll-2-HA (b), or Toll-8-HA

(c) expressed with engrailed-Gal4. Myosin II (green, white), HA (red). Arrows, anterior boundary of the engrailed domain. Ventral views. Bar, $10 \mu \mathrm{m}$. (d) Myosin levels are increased at the posterior boundary of Toll-2 stripes in eve mutants $(p=0.00001)$. All edges oriented $75-90^{\circ}$ relative to the AP axis (AP) or edges only at anterior (Ant) or posterior (Post) boundaries of Toll-2 stripes; edge values were normalized to average edge intensity. (e) Myosin levels are increased at the anterior boundary of ectopic Toll-2 and Toll- 8 expression. (f) Peak retraction velocities following laser ablation are increased at the anterior boundary of ectopic Toll- 8 expression. Horizontal line, median; boxes, $2^{\text {nd }}$ and $3^{\text {rd }}$ quartiles; whiskers, $5^{\text {th }}$ to $95^{\text {th }}$ percentile. Single average values were obtained for each embryo; plots show the distribution of values across embryos. * $p \unlhd 0.008, * * p \$ 0.0001$ (unpaired t-test). (d,e) n=6-15 embryos/genotype, (f) n=16-17 ablations/genotype (Supplementary Table 2). 

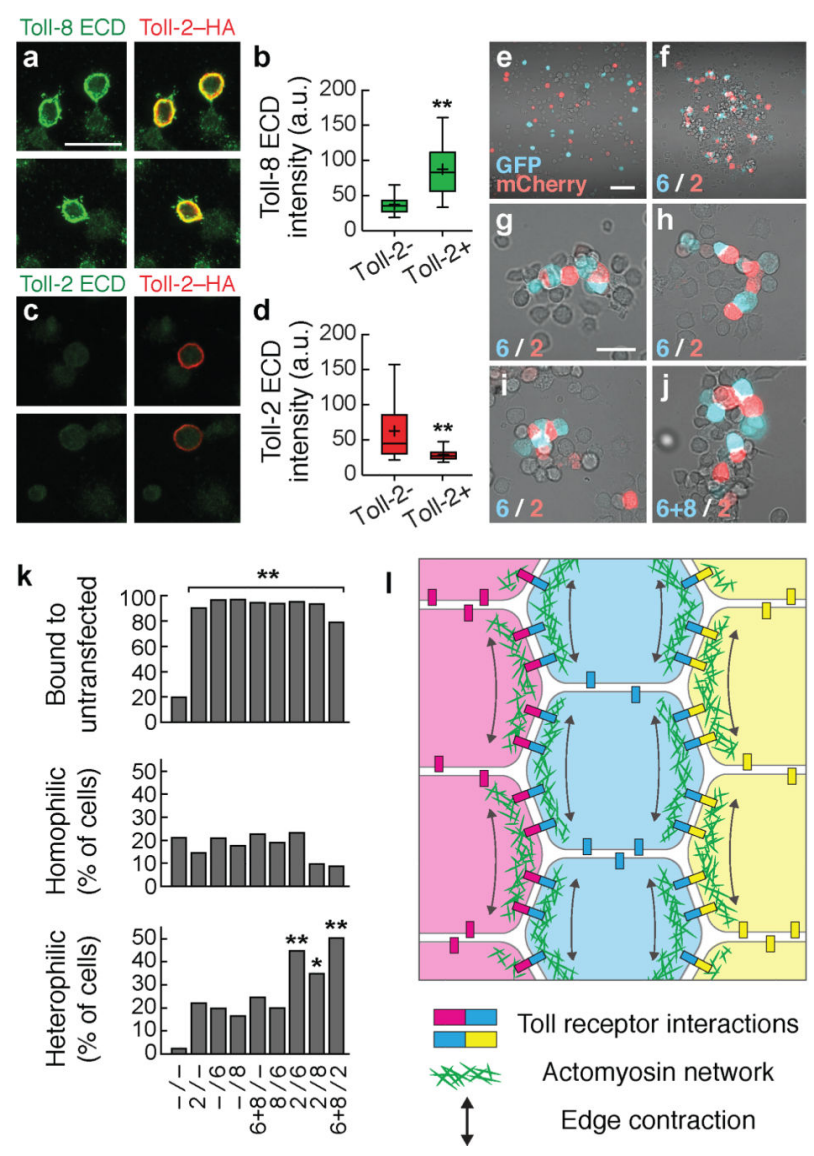

Figure 5. Toll receptors mediate heterophilic interactions between cells (a-d) Drosophila S2R + cells expressing Toll-2-HA (red) incubated with pentamerized Toll-8 (a,b) or Toll-2 (c,d) extracellular domains (ECD) (green). Toll-8 ECD bound more strongly (b) and Toll-2 ECD bound less strongly (d) to Toll-2-positive (Toll-2+) cells compared with Toll-2-negative (Toll-2-) cells ( $p<0.00001$, unpaired t-test). Horizontal line, median; boxes, $2^{\text {nd }}$ and $3^{\text {rd }}$ quartiles; whiskers, $5^{\text {th }}$ to $95^{\text {th }}$ percentile. (e-k) Interactions between cells expressing myosin-GFP (cyan, listed first) or myosin-mCherry (red, listed second) with the indicated Toll receptors (-, myosin marker alone). Receptor-expressing cells displayed increased binding to untransfected cells ( $p \unlhd 0.0001$, Chi-square test). Heterophilic binding was increased between cells expressing Toll-2 and Toll-6 ( $p \unlhd 0.0003)$, Toll-2 and Toll-8 ( $p<0.05)$, and Toll-2 and Toll-6+Toll-8 ( $p \unlhd 0.0001$ ) (Chi-square test). * $p=0.01-0.05$, $* * p \unlhd 0.0003$. (l) Model: heterophilic interactions between Toll receptors recruit myosin II, promoting oriented cell rearrangements and convergent extension. (b,d) $n=170-176$ cells/ condition, (k) $\mathrm{n}=85-123$ transfected cells/condition (Supplementary Table 2). Bars, $20 \mu \mathrm{m}$ (a,c,g-j), $100 \mu \mathrm{m}(\mathrm{e}, \mathrm{f})$. 